\title{
Theoretical Analysis on Mechanical Behavior of Axially Loaded Recycled Aggregate Concrete Filled Steel Tubes
}

\author{
Yijie Huang, Yuedong Sun, Huangsheng Sun, and Qing Wang \\ Department of Civil Engineering, Shandong University of Science and Technology, 579 Qianwangang Road, \\ Economic \& Technical Development Zone, Qingdao 266510, China
}

Correspondence should be addressed to Yijie Huang; 302huangyijie@163.com

Received 4 July 2015; Accepted 2 September 2015

Academic Editor: Giovanni Falsone

Copyright (c) 2015 Yijie Huang et al. This is an open access article distributed under the Creative Commons Attribution License, which permits unrestricted use, distribution, and reproduction in any medium, provided the original work is properly cited.

A new mechanical model for analysing the behaviour of axially loaded recycled aggregate concrete filled steel tubes (RACFSTs) stub columns is presented in this study. The model is derived from the typical elastoplasticity, the nonlinear elastic mechanics, and the properties of materials. Based on the mechanical model, a novel numerical program is developed. The mechanical model and the numerical program are adopted to study the effect of recycled coarse aggregate (RCA) replacement percentage on RACFST mechanical behaviour. The complete load-deformation relationship of specimens, the steel tube axial and circumferential stresses, and the performance of the confined core concrete and the variation of interaction are also investigated. The analytical results indicate that this model is able to capture the mechanical behaviour of RACFST. It is also found that the axial and circumferential stresses of steel tube change nonlinearly during the loading stages. It is concluded that the behaviour of the confined core concrete is significantly influenced by the confining pressure. The steel tube confinement could improve the mechanical behaviour of RAC effectively and the RCA replacement percentage slightly changes the response of core concrete. Finally, the relations between confined core concrete and confining pressure are analysed.

\section{Introduction}

Recycled aggregate concrete (RAC) can partly or totally substitute natural aggregates with recycled aggregates. It is an important kind of green materials. Since the old mortar is attached to the recycled coarse aggregate (RCA), the mechanical properties of recycled concrete are complicated. The features of RAC could be characterized by low compressive strength and elastic modulus [1,2], high shrinkage and creep $[3,4]$, and inferior durability and deformation $[5,6]$. So the development and application of RAC are somewhat restricted due to the above-mentioned shortcomings. RAC filled steel tubes (RACFSTs) are considered one of the best way to improve the properties of recycled aggregate concrete. The core concrete has no moisture exchange with the surroundings under the confinement by steel tube. Shrinkage of the core concrete is limited by the outer tube. Creep of the confined concrete is different and smaller than that of ordinary concrete [7-10]. Moreover, the axial compressive strength and the deformation performance are improved because the extension of internal microcracks is restricted [11, 12]. As an excellent structure system, the performance of RACFST has been studied, especially the mechanical behaviour of RACFST stub columns under axial compression.

Many experimental studies on RACFST stub columns have been carried out. Konno and Sato [13] tested the columns with different RCA contents and studied its mechanical behaviour. It was found that the modulus and strength were lower than those of ordinary concrete filled steel tubes (CFSTs). Yang [14] carried out studies on the RACFST stub columns and presented the stress-strain relationships of the confined RAC. Chen and Zeng [15] and Chen et al. $[16,17]$ studied the behaviour of 22 RACFSTs and developed an experimental model for calculating the axial loaddeformation relationship. It proved that the RCA replacement percentage could influence the members' mechanical behaviour. Xiao et al. [18] conducted a series of RACFST stub column tests. A simplified axial stress-strain curve of RACFST which is based on the test results was also provided. It was found that the ductility and bearing capacity were 
improved due to the interaction between the steel tube and the core concrete. Liu et al. [19] and Wu et al. [20] studied the mechanical behaviour of RACFST stub column under axial compression. It was concluded that circular steel tubes offered much higher postyield axial ductility than the square or rectangular tube sections.

The above experimental studies and the simplified models could produce relatively accurate load-deformation curves, which provide an understanding of RACFST mechanical behaviour. But they could not fully reflect the composite action between the outer tube and the core concrete and are limited by the number of specimens. Therefore, many researchers have used numerical method to evaluate the mechanical behaviour of axially loaded RACFST stub columns. Xiao et al. [18] used commercial finite element method (FEM) software to analyze the performance of RACFST columns. It was found that the load-deformation relationship of specimen was influenced by the material strength and the constraining factor. Yang [14] adopted the fibre mechanical model [21] to simulate the mechanical behaviour of circular RACFST short columns under axial loading. It was found that the peak strain of specimen increased with an increase of RCA replacement percentage. However, among the above numerical models, the commercial FEM is restricted due to its disadvantages. The users could not fully understand the contents of commercial FEM software, so the accuracy of results is difficult to estimate. Also, the parameter values in fibre mechanical model are obtained from the measured RACFST specimens, and the constitutive relations are not clear when the steel enters into plastic stage. Additionally, the numerical research on RACFST is still in its early stage. The quantitative analysis on the RCA replacement percentage and the steel tube confinement effects need to be further studied. So, for accurately studying the behaviour of RACFST stub columns, a mechanical model based on the rigorous mechanics theory needs to be built.

In this paper, a mechanical model is developed to evaluate the complete load-deformation relationship of specimens, the steel tube axial and circumferential stresses, the performance of the confined core concrete, and the RCA influence. Based on the typical elastoplasticity and the nonlinear elasticity, the calculated model and the corresponding numerical program are developed. The related experimental results in literature are used to validate the proposed model.

\section{Mechanical Model}

In this study, the mechanical behaviour of RACFST stub columns is analysed based on the cross-sectional analysis method, which adopts some assumptions to study the mechanical behaviour. The assumptions, the equilibrium equation, the deformation compatibility, and the constitutive model are proposed according to the axial loading conditions. The notations for symbols of equations are listed as follows: $N$ and $\triangle$ are load and displacement, respectively; $\sigma$ and $\varepsilon$ represent stress and strain, respectively; $c$ and $s$ denote concrete and steel, respectively; $a, h$, and $r$ are the axial, hoop, and radial directions, respectively; $\mu$ is Poisson's ratio.

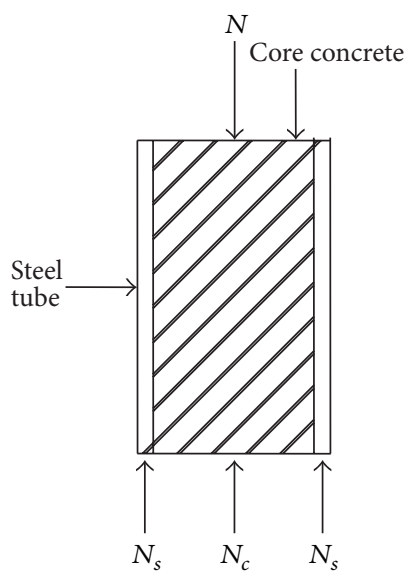

(a) RACFST

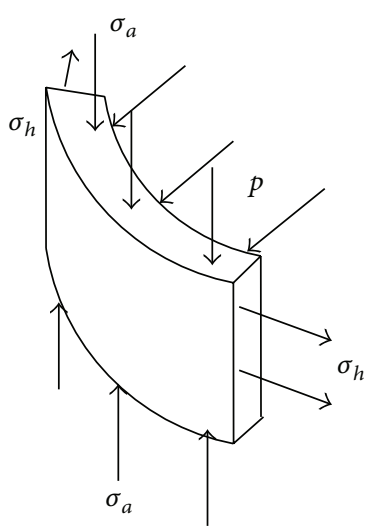

(b) Steel tube
FIGURE 1: The loading conditions of specimens.

2.1. Basic Assumptions. The following assumptions are made:

(1) The core concrete and the outer steel tube are under triaxial stress conditions. The effect of radial stress on outer tube is considered.

(2) The local buckling of the outer steel tube is ignored due to the support of core concrete. The slippage between concrete and steel tube is not considered.

(3) The core concrete is under uniform confining pressure conditions, and the deformation and stress of specimens are averaged.

(4) The model is applicable to circular CFST stub columns with the length-to-diameter ratio of 2.0-4.5, the diameter-to-thickness ratio ranges from 15 to 155 , and the confining factor is $0.15 \leq \xi \leq 4.5$.

It should be noted that the load from the axial direction is supported by the infilled concrete and the outer steel tube, and the axial and radial deformations of steel tube are compatible with those of core concrete. So, the local buckling of steel is relieved effectively. The influence of bond-slip on the mechanical behavior of CFST is not obvious [22]. The effects of local buckling and slippage are not considered in this paper.

2.2. Equilibrium Equation. The load from the axial direction is supported by the infilled concrete and the outer steel tube (Figure 1). The equilibrium equations of outer tube and core concrete are

$$
\begin{aligned}
N & =N_{c}+N_{s}, \\
\sigma_{c}^{r} & =p, \\
p & =-2 \frac{t}{D} \sigma_{s}^{h},
\end{aligned}
$$

where $N, N_{c}$, and $N_{s}$ are the axial loads of specimen, core concrete, and steel tube, respectively, $\sigma_{c}^{r}$ and $p$ are the radial stress of concrete and the confining pressure, $\sigma_{s}^{h}$ is 


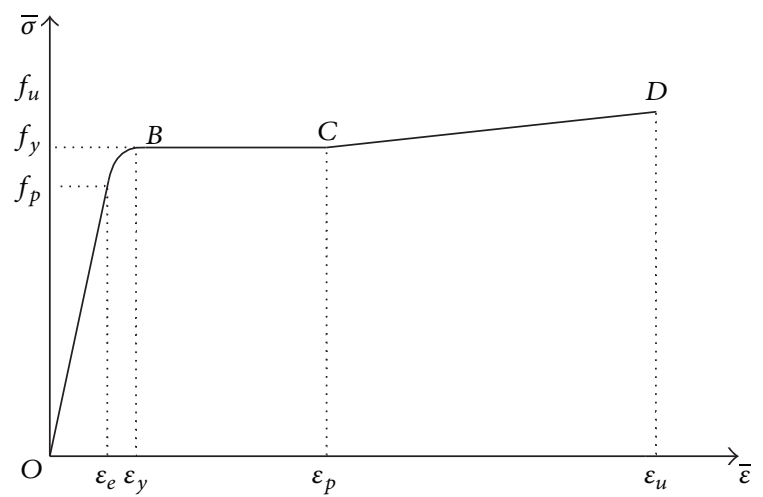

FIgURE 2: The equivalent stress-strain relationship of steel.

the circumferential stress of the steel tube, and $t$ and $D$ are the thickness and diameter of the outer tube, respectively.

2.3. Deformation Compatibility. Under the axial compression, the axial deformations of the outer tube and the core concrete are identical. The radial deformation of the core concrete should be compatible with that of the outer tube:

$$
\begin{aligned}
\Delta_{c}^{a} & =\Delta_{s}^{a}, \\
\Delta_{c}^{r}+\Delta_{s}^{r} & =\Delta_{s}^{h} .
\end{aligned}
$$

In (4)-(5), $\Delta_{c}^{a}$ and $\Delta_{s}^{a}$ are the axial displacements of the core concrete and the steel tube, respectively, $\Delta_{s}^{r}$ and $\Delta_{s}^{h}$ are the radial and circumferential displacements of the steel tube, respectively, and $\Delta_{c}^{r}$ denotes radial displacement of the core concrete.

2.4. Constitutive Model for Steel Tube. The equivalent stressstrain relationship [23] of steel is used to evaluate the stress state of the steel tube during the whole loading stages (see Figure 2). It can be divided into four stages: elastic stage, elastic-plastic stage, yield stage, and strain hardening stage. The equations for each stage are listed as follows.

2.4.1. The Elastic Stage. In the elastic stage, the equivalent strain $\bar{\varepsilon}$ is proportional to the equivalent stress $\bar{\sigma}$ when $\bar{\sigma} \leq$ $0.8 f_{y}$. The constitutive relationships between $\bar{\sigma}$ and $\bar{\varepsilon}$ can be obtained by Hooke's law. The following equations are applied to obtain the stress and strain state of the steel in this stage:

$$
\begin{aligned}
\sigma_{s}^{a} & =\frac{E_{s}}{\left(1-2 \mu_{s}\right)\left(1+\mu_{s}\right)}\left[\varepsilon_{s}^{a}\left(1-\mu_{s}\right)+\mu_{s}\left(\varepsilon_{s}^{h}+\varepsilon_{s}^{r}\right)\right], \\
\sigma_{s}^{h} & =\frac{E_{s}}{\left(1-2 \mu_{s}\right)\left(1+\mu_{s}\right)}\left[\varepsilon_{s}^{h}\left(1-\mu_{s}\right)+\mu_{s}\left(\varepsilon_{s}^{a}+\varepsilon_{s}^{r}\right)\right], \\
\sigma_{s}^{r} & =-\frac{t \sigma_{s}^{h}}{D} \\
\varepsilon_{s}^{r} & =\frac{1}{E_{s}}\left[-\frac{t \sigma_{s}^{h}}{D}-\mu_{s}\left(\sigma_{s}^{a}+\sigma_{s}^{h}\right)\right],
\end{aligned}
$$

where $\sigma_{s}^{a}$ and $\sigma_{s}^{r}$ are the axial and radial stresses of the steel tube, respectively, $\varepsilon_{s}^{a}, \varepsilon_{s}^{h}$, and $\varepsilon_{s}^{r}$ denote the axial, circumferential, and radial strains of the steel tube, respectively, $E_{s}$ is the elastic modulus, and $\mu_{s}$ is Poisson's ratio of steel tube, respectively.

2.4.2. The Elastic-Plastic Stage. In this stage, $\bar{\varepsilon}$ is nonproportional to $\bar{\sigma}$ when $0.8 f_{y}<\sigma \leq f_{y}$. The generalized Hooke's law is adopted. The following equations are used to obtain the stress and strain state of the steel in this stage:

$$
\begin{aligned}
d \sigma_{s}^{a} & =\frac{E_{s}^{\prime}}{\left(1-2 \mu_{s}^{\prime}\right)\left(1+\mu_{s}^{\prime}\right)}\left[\varepsilon_{s}^{a}\left(1-\mu_{s}^{\prime}\right)+\mu_{s}^{\prime}\left(\varepsilon_{s}^{h}+\varepsilon_{s}^{r}\right)\right], \\
d \sigma_{s}^{h} & =\frac{E_{s}^{\prime}}{\left(1-2 \mu_{s}^{\prime}\right)\left(1+\mu_{s}^{\prime}\right)}\left[\varepsilon_{s}^{h}\left(1-\mu_{s}^{\prime}\right)+\mu_{s}^{\prime}\left(\varepsilon_{s}^{a}+\varepsilon_{s}^{r}\right)\right], \\
d \sigma_{s}^{r} & =-\frac{t d \sigma_{s}^{h}}{D} \\
d \varepsilon_{s}^{r} & =\frac{1}{E_{s}^{\prime}}\left[-\frac{t d \sigma_{s}^{h}}{D}-\mu_{s}^{\prime}\left(d \sigma_{s}^{a}+d \sigma_{s}^{h}\right)\right], \\
E_{s}^{\prime} & =\frac{\left(f_{y}-\bar{\sigma}\right) \bar{\sigma}}{\left(f_{y}-0.8 f_{y}\right) 0.8 f_{y}} E_{s}, \\
\mu_{s}^{\prime} & =0.167 \frac{\left(\bar{\sigma}-0.8 f_{y}\right)}{\left(f_{y}-0.8 f_{y}\right)}+0.283,
\end{aligned}
$$

where $E_{s}^{\prime}$ and $\mu_{s}^{\prime}$ are the modulus and Poisson's ratio of steel tube in the elastic-plastic stage, respectively [24], $d \sigma_{s}^{a}$, $d \sigma_{s}^{h}$, and $d \sigma_{s}^{r}$ are the axial, circumferential, and radial stress increments of the steel tube, respectively, and $d \varepsilon_{s}^{a}, d \varepsilon_{s}^{h}$, and $d \varepsilon_{s}^{r}$ are the axial, circumferential, and radial strain increments of the steel tube, respectively.

2.4.3. The Yield Stage. The steel is in the yield plateau when $\bar{\sigma}=f_{y}$ and $\varepsilon_{y} \leq \varepsilon_{i} \leq \varepsilon_{p}$. The Von-Mises criterion, the Prandtl-Reuss incremental theory of plasticity, and the associate flow rules are adopted. The equations in this stage could be found in Huang et al. [25].

2.4.4. The Strain Hardening Stage. In the strain hardening stage, the relationships between stress and strain can be obtained by the Prandtl-Reuss incremental theory of plasticity. The equations could be obtained in literature [25].

In the above equations, $\bar{\sigma}$ and $\bar{\varepsilon}$ can be expressed as

$$
\begin{aligned}
& \bar{\sigma}=\sqrt{\frac{1}{2}}\left[\left(\sigma_{s}^{r}-\sigma_{s}^{h}\right)^{2}+\left(\sigma_{s}^{r}-\sigma_{s}^{a}\right)^{2}+\left(\sigma_{s}^{h}-\sigma_{s}^{a}\right)^{2}\right]^{0.5}, \\
& \bar{\varepsilon}=\frac{\sqrt{2}}{3}\left[\left(\varepsilon_{s}^{r}-\varepsilon_{s}^{h}\right)^{2}+\left(\varepsilon_{s}^{r}-\varepsilon_{s}^{a}\right)^{2}+\left(\varepsilon_{s}^{h}-\varepsilon_{s}^{a}\right)^{2}\right]^{0.5} .
\end{aligned}
$$

2.5. Constitutive Model for Core Concrete. In this paper, the nonlinear elastic constitutive model is adopted due to its 
clarity, simplicity, and good agreement with experimental results under monotonic loading conditions [26].

The nonlinear elastic constitutive model is composed of two parts: the failure criterion and the stress-strain relationship.

2.5.1. The Failure Criterion. The modified Hsieh-Ting-Chen $[27,28]$ four-parameter criterion is adopted. The criterions for normal concrete (NC) and RAC are defined by

$$
\begin{aligned}
& 8.941 \frac{J_{2}}{f_{c}^{2}}-2.430 \frac{\sqrt{J_{2}}}{f_{c}}+11.668 \frac{\sigma_{1}}{f_{c}}+0.577 \frac{I_{1}}{f_{c}}-1 \\
& =0 \text { (RAC) }, \\
& 7.644 \frac{J_{2}}{f_{c}^{2}}-1.793 \frac{\sqrt{J_{2}}}{f_{c}}+10.268 \frac{\sigma_{1}}{f_{c}}+0.513 \frac{I_{1}}{f_{c}}-1 \\
& =0(\mathrm{NC}),
\end{aligned}
$$

where $f_{c}$ is the prism compressive strength of concrete, $I_{1}$ is the first stress invariant, $J_{2}$ is the second stress invariant, and $\sigma_{1}$ is the first principal stress.
2.5.2. The Stress-Strain Relation. The isotropic incremental nonlinear elastic stress-strain relation [29] is expressed as follows:

$$
\left\{\begin{array}{l}
d \varepsilon_{c}^{a} \\
d \varepsilon_{c}^{h} \\
d \varepsilon_{c}^{r}
\end{array}\right\}=\left[\begin{array}{rrr}
\frac{1}{E_{c}^{t}} & -\frac{\mu_{c}^{t}}{E_{c}^{t}} & -\frac{\mu_{c}^{t}}{E_{c}^{t}} \\
-\frac{\mu_{c}^{t}}{E_{c}^{t}} & \frac{1}{E_{c}^{t}} & -\frac{\mu_{c}^{t}}{E_{c}^{t}} \\
-\frac{\mu_{c}^{t}}{E_{c}^{t}} & -\frac{\mu_{c}^{t}}{E_{c}^{t}} & \frac{1}{E_{c}^{t}}
\end{array}\right]\left\{\begin{array}{l}
d \sigma_{c}^{a} \\
d \sigma_{c}^{h} \\
d \sigma_{c}^{r}
\end{array}\right\},
$$

where $E_{c}^{t}$ (20) and $\mu_{c}^{t}$ (21) [29] are the tangent modulus and tangent Poisson's ratio of concrete, respectively, $d \varepsilon_{c}^{a}, d \varepsilon_{c}^{h}$, and $d \varepsilon_{c}^{r}$ denote the axial, circumferential, and radial strain increments of concrete, respectively, and $d \sigma_{c}^{a}, d \sigma_{c}^{h}$, and $d \sigma_{c}^{r}$ are the axial, circumferential, and radial stress increments of concrete, respectively. Consider

$$
\begin{aligned}
& E_{c}^{t}= \begin{cases}E_{o}+2\left[3-2\left(\frac{E_{o}}{E_{f}}\right)\right]\left(\frac{\varepsilon}{\varepsilon_{i}}\right) E_{f}+3\left[\left(\frac{E_{o}}{E_{f}}\right)-2\right]\left(\frac{\varepsilon}{\varepsilon_{i}}\right)^{2} E_{f} & \beta \leq 1 \\
\frac{\eta E_{f}\left[0.8-0.8\left(\varepsilon / \varepsilon_{i}\right)^{2}\right]}{\left[\left(\varepsilon / \varepsilon_{i}\right)+0.8\left(\varepsilon / \varepsilon_{i}-1\right)^{2}\right]^{2}} & \beta>1,\end{cases} \\
& \mu_{c}^{t}= \begin{cases}\mu_{o} & \beta \leq 0.6 \\
\mu_{f}-\left(\mu_{f}-\mu_{o}\right) \sqrt{1-(5 \beta-3)^{2}} & 0.6<\beta \leq 1 \\
\mu_{f} & \beta>1,\end{cases} \\
& E_{f}=\frac{\sigma_{i}}{\varepsilon_{i}}, \\
& \sigma_{i}=f_{c}\left\{1+\frac{\left[2.15(2 t / D) f_{y}\left(28 / f_{c u}\right)^{0.15}\right]}{f_{c}}\right\} \\
& \varepsilon_{i}=5\left[\left(\frac{\sigma_{i}}{f_{c}}\right)^{0.8}-0.8\right](-0.0475 r+1.0624)\left(0.833+0.121 \sqrt{f_{c u}}\right) \times 10^{-3} \text {, } \\
& \eta=0.0236^{\left(\ln \left(p / p_{1}\right)\right)^{2}},
\end{aligned}
$$

where $E_{o}$ is the elastic modulus of concrete, $\varepsilon$ is the strain of concrete, $\mu_{o}=0.23$ and $\mu_{f}=1.08$ [26] denote the initial Poisson's ratio and peak tangent Poisson's ratio of concrete, respectively, $r$ is the RAC replacement percentage $(0.7 \leq r \leq$ 1), $\beta$ [29] is the nonlinear index, $p$ denotes the confining pressure, and $p_{1}$ is the confining pressure when the axial stress of concrete first descends.

\section{Analytical Procedure}

For the analysis of the mechanical behaviour of RACFST stub columns under concentric compression, a total of twenty unknown variables are defined $\left(\sigma_{c}^{a}, \sigma_{c}^{h}, \sigma_{c}^{r}, \sigma_{s}^{a}, \sigma_{s}^{h}, \sigma_{s}^{r}, p\right.$, $\varepsilon_{c}^{a}, \varepsilon_{c}^{h}, \varepsilon_{c}^{r}, \varepsilon_{s}^{a}, \varepsilon_{s}^{h}, \varepsilon_{s}^{r}, E_{c}^{t}, \mu_{c}^{t}, E_{s}^{\prime}, \mu_{s}^{\prime}, N, \bar{\sigma}$, and $\left.\bar{\varepsilon}\right)$. Also, there are twenty independent equations in the above constitutive 


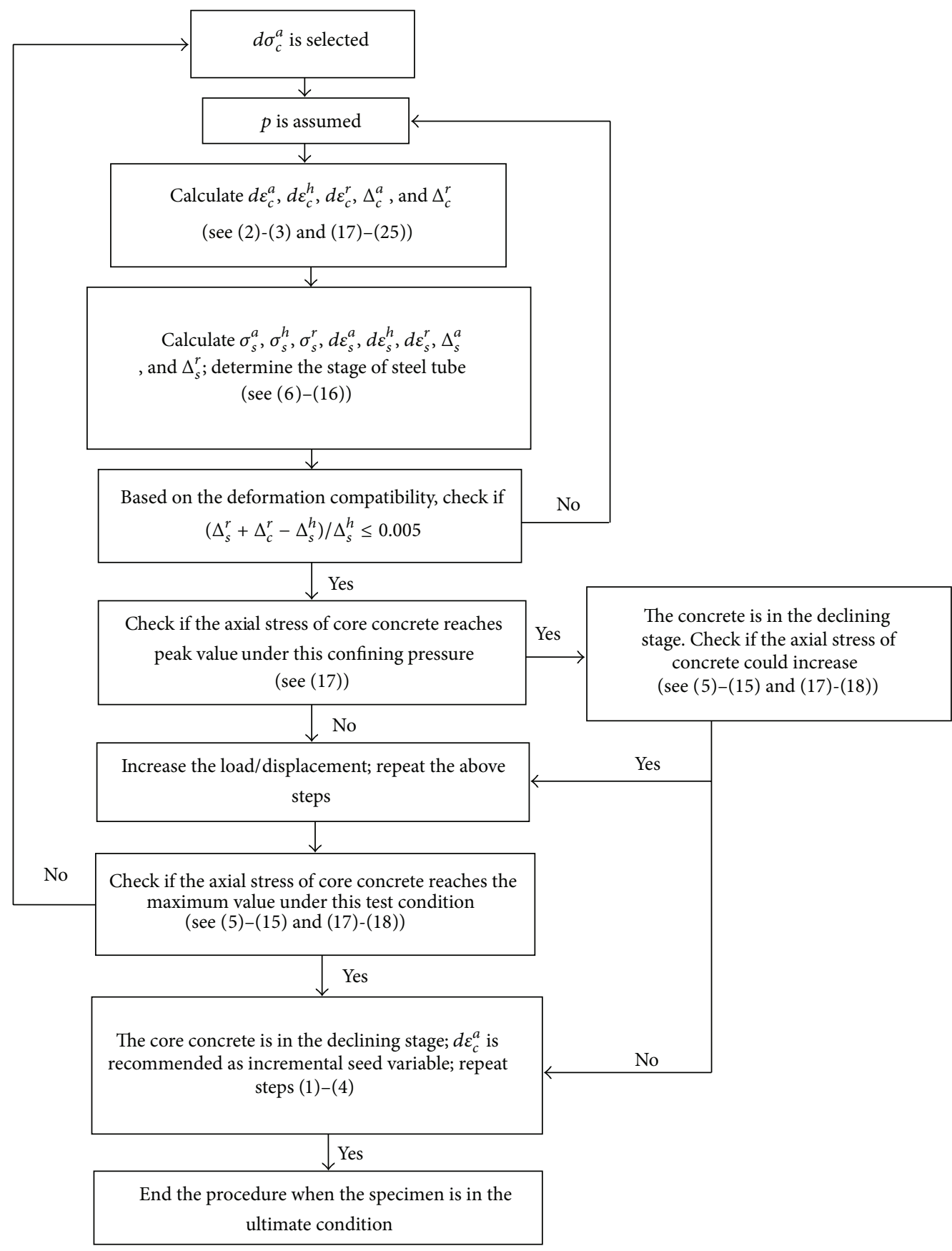

FIGURE 3: The numerical program.

model (see (1)-(11), (13)-(17)/(18), and (19)-(21)). So, the unknown variables can be solved. The incremental analysis method is adopted. The axial stress value of the core concrete is selected as the incremental seed variable before the peak stress while the axial strain value is used after the peak stress (the exact peak stress is obtained based on the calculation). The numerical program is shown in Figure 3. The detailed procedures for this program can be summarized in the following steps:

(1) A value of axial stress (strain) is fixed.
(2) A confining pressure is assumed.

(3) The deformations of core concrete and steel tube are calculated (see (2)-(25)).

(4) Check if the radical deformation of concrete is compatible with that of the outer tube. If not, go back to step (2).

(5) If the deformations satisfy the regulation, check if the axial stress of core concrete reaches peak value (see (17)-(18)). If yes, the concrete is in the decline stage under this confining pressure. 


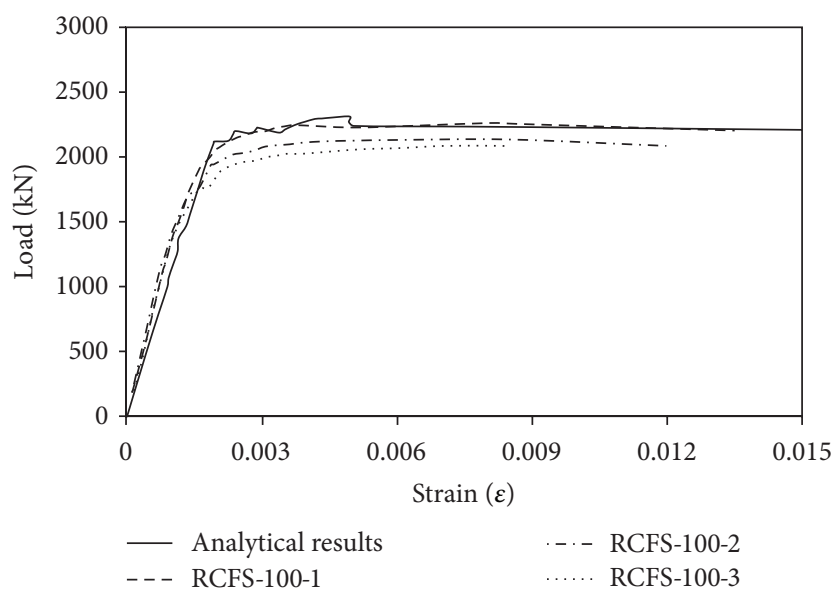

(a) RCFS-100

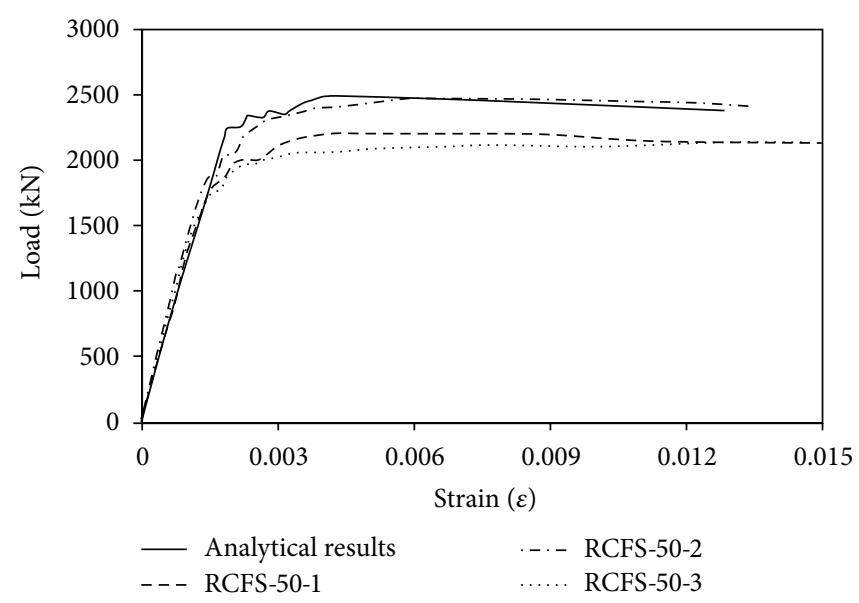

(c) RCFS-50

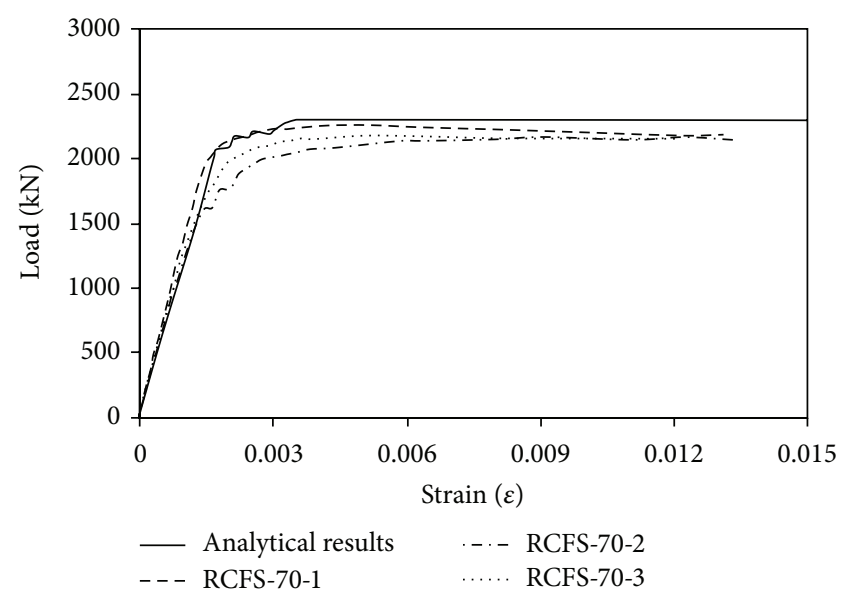

(b) RCFS-70

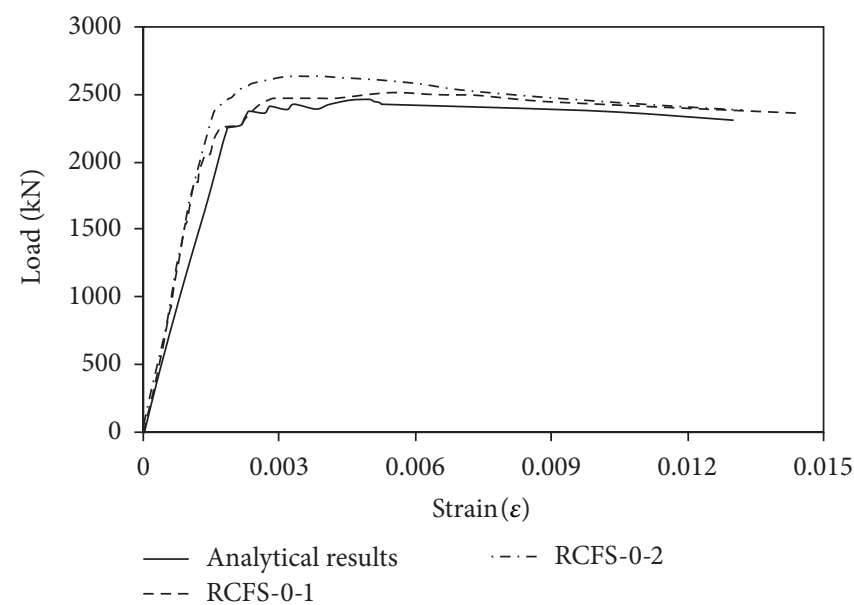

(d) RCFS-0

FIgURE 4: The axial load-strain relationships of specimens [18].

(6) If the axial stress of core concrete does not reach peak value, repeat the above steps and increase the axial stress until it reaches peak point under this test condition.

(7) The core concrete is in the declining stage; a value of axial strain is selected as incremental seed variables. Repeat steps (1)-(4), and obtain the load-deformation relationship for specimen.

It should be noted that the increment of axial stress becomes smaller when approaching the peak point. The Fortran 95 software is used to code the numerical program according to this procedure.

\section{Comparisons with Experimental Results}

The accuracy of the mechanical model is checked against the following experimental results summarized in Table 1.

4.1. Experiment of Xiao et al. [18]. Xiao et al. [18] carried out axial compression tests on RACFST stub columns. The load-deformation relation, the bearing capacity, and the deformation ability were studied. Four sets of test results
(RCFS-0, RCFS-50, RCFS-70, and RCFS-100) are applicable to the analytical solution of this study and selected to verify this mechanical model.

The comparisons between the experimental and the analytical results are shown in Figure 4. It is found that the load-deformation relationship of RACFST can be divided into elastic stage, elastic-plastic stage, and declining stage. The calculated curve is nearly the same as the experimental ones. The average calculated peak loads of RCFS-100, RCFS70, RCFS-50, and RCFS- 0 are $2,311 \mathrm{kN}, 2,298 \mathrm{kN}, 2,500 \mathrm{kN}$, and $2,458 \mathrm{kN}$, about $4.6 \%, 5.3 \%, 8.7 \%$, and $-2.2 \%$ higher than the experimental $2,210 \mathrm{kN}, 2,182 \mathrm{kN}, 2,299 \mathrm{kN}$, and $2,513 \mathrm{kN}$, respectively. The calculated peak strains are close to the experimental ones.

The experimental [25] and analytical strains of the steel tube are compared in Figure 5. It is found that the circumferential strain is small in the initial loading stage, which means that the composition action between the steel tube and the core concrete is negligible. As the load increases, the circumferential strain quickly increases and finally exceeds the axial strain. The calculated ones are similar to the experimental results. 
TABLE 1: The detailed specimen.

\begin{tabular}{|c|c|c|c|c|c|c|c|c|c|}
\hline & Specimen & $\begin{array}{c}D \\
(\mathrm{~mm})\end{array}$ & $\begin{array}{c}t \\
(\mathrm{~mm})\end{array}$ & $\begin{array}{c}f_{c} \\
(\mathrm{MPa})\end{array}$ & $\begin{array}{c}f_{y} \\
(\mathrm{MPa})\end{array}$ & $\xi$ & $r$ & $\begin{array}{c}N_{u} \\
(\mathrm{kN})\end{array}$ & $\begin{array}{l}N_{u}^{c} \\
(\mathrm{kN})\end{array}$ \\
\hline \multirow{11}{*}{ Xiao et al. [18] } & RCFS-100-1 & 200 & 3.63 & 29.6 & 465 & \multirow{3}{*}{1.21} & \multirow{3}{*}{$100 \%$} & \multirow{3}{*}{2210} & \multirow{3}{*}{2311} \\
\hline & RCFS-100-2 & 200 & 3.63 & 29.6 & 465 & & & & \\
\hline & RCFS-100-2 & 200 & 3.63 & 29.6 & 465 & & & & \\
\hline & RCFS-70-1 & 200 & 3.63 & 27.9 & 465 & \multirow{3}{*}{1.28} & \multirow{3}{*}{$70 \%$} & \multirow{3}{*}{2182} & \multirow{3}{*}{2298} \\
\hline & RCFS-70-2 & 200 & 3.63 & 27.9 & 465 & & & & \\
\hline & RCFS-70-3 & 200 & 3.63 & 27.9 & 465 & & & & \\
\hline & RCFS-50-1 & 200 & 3.63 & 34.7 & 465 & \multirow{3}{*}{1.03} & \multirow{3}{*}{$50 \%$} & \multirow{3}{*}{2299} & \multirow{3}{*}{2500} \\
\hline & RCFS-50-2 & 200 & 3.63 & 34.7 & 465 & & & & \\
\hline & RCFS-50-3 & 200 & 3.63 & 34.7 & 465 & & & & \\
\hline & RCFS-0-1 & 200 & 3.63 & 35.9 & 465 & \multirow{2}{*}{1.00} & \multirow{2}{*}{$0 \%$} & \multirow{2}{*}{2513} & \multirow{2}{*}{2458} \\
\hline & RCFS-0-2 & 200 & 3.63 & 35.9 & 465 & & & & \\
\hline \multirow{2}{*}{ Chen and Zeng [15] } & $\mathrm{C}-2$ & 127 & 4.20 & 57.8 & 298.3 & 0.76 & $60 \%$ & 1568 & 1413 \\
\hline & $\mathrm{C}-3$ & 127 & 4.20 & 52.0 & 298.3 & 0.85 & $100 \%$ & 1463 & 1333 \\
\hline \multirow{4}{*}{ Johansson [22] } & SFE8 & 159 & 6.5 & 93.8 & 402 & \multirow{2}{*}{0.80} & \multirow{2}{*}{$0 \%$} & \multirow{2}{*}{3310} & \multirow{2}{*}{3396} \\
\hline & SFC8 & 159 & 6.5 & 93.8 & 402 & & & & \\
\hline & SFE9 & 159 & 10.0 & 93.8 & 355 & \multirow{2}{*}{1.17} & \multirow{2}{*}{$0 \%$} & \multirow{2}{*}{3765} & \multirow{2}{*}{3806} \\
\hline & SFC9 & 159 & 10.0 & 93.8 & 355 & & & & \\
\hline \multirow{2}{*}{ Yang [14] } & CA1 & 114 & 2.19 & 28.0 & 335.7 & 0.98 & $25 \%$ & 705 & 686 \\
\hline & CA2 & 114 & 2.19 & 24.5 & 335.7 & 1.11 & $50 \%$ & 672 & 636 \\
\hline \multirow{3}{*}{ Huang et al. [30] } & CU-40 & 200 & 5 & 27.15 & 265.8 & 1.06 & $0 \%$ & 2013 & 2026 \\
\hline & CU-70 & 280 & 4 & 31.15 & 272.6 & 0.52 & $0 \%$ & 3025 & 3009 \\
\hline & CU-150 & 300 & 2 & 27.23 & 341.7 & 0.34 & $0 \%$ & 2608 & 2485 \\
\hline
\end{tabular}

$N_{u}$ is the maximum experimental load of specimen; $N^{c}{ }_{u}$ is the calculated one.

The development of axial stress $\left(\sigma_{s}^{a}\right)$ of the steel tube is shown in Figure 6. It can be found that $\sigma_{s}^{a}$ does not remain constant or elastic-plastic during the loading period. The calculated peak value of $\sigma_{s}^{a}$ is $372.87 \mathrm{MPa}$, only $6.8 \%$ higher than the average experimental peak stress $348.91 \mathrm{MPa}$. The development of $\sigma_{s}^{a}$ can be divided into linear elastic stage, hardening stage, declining stage, and nearly plastic stage.

4.2. Experiment of Chen and Zeng [15]. Chen and Zeng [15] studied the mechanical behaviour of 6 circular RACFST stub columns. Two typical specimens are selected to verify the model.

The comparisons between the experimental results and the analytical results are shown in Figure 7. It can be found that the load-displacement relationship can be divided into linear increasing, nonlinear increasing, and declining stages. The declining tendency of Chen's experimental curve is more obvious than that of Xiao's results, which is attributed to the lower constraining factor $\xi$. The predicted curves are similar to the experimental ones. The calculated peak loads are $1,333 \mathrm{kN}$ and $1,413 \mathrm{kN}$, about $9.75 \%$ and $9.89 \%$ lower than the experimental $1,463 \mathrm{kN}$ and $1,568 \mathrm{kN}$, respectively.

4.3. Experiment of Yang [14]. Yang [14] investigated the mechanical behaviour of RACFST stub columns under different RCA replacement percentages, section types, material strengths, and constraining factors. A total of 10 specimens are tested. Two typical sets of circular section specimens are analysed by the numerical program.
The predicted and experimental curves are shown in Figure 8. The analytical results are close to the real ones. The predicted peak loads are $686 \mathrm{kN}$ and $636 \mathrm{kN}$, about $3.70 \%$ and $5.66 \%$ lower than the experimental $705 \mathrm{kN}$ and $672 \mathrm{kN}$, respectively. The peak loads of specimens are closely estimated. Figure 8 also compares the analytical results with the fibre mechanical model results suggested by Han et al. [21]. It is found that the differences are slight, while the peak loads calculated by the fibre mechanical model are $648 \mathrm{kN}$ and $624 \mathrm{kN}$, about $5.9 \%$ and $1.8 \%$ lower than the analytical ones. The model could well reflect the mechanical behaviour of RACFST.

4.4. Experiments of Johansson [22] and Huang et al. [30]. Johansson [22] studied the mechanical behaviour of 15 circular CFST stub columns. Two sets of test results are selected to verify the analytical solution of mechanical model. Huang et al. [30] executed experiments on 17 specimens. In this experiment, only three concrete filled steel tube columns without stiffness were tested, each column with different diameter-to-thickness ratios.

Figures 9 and 10 show the experimental and analytical load-deformation relationships. The load-deformation response of specimens can be divided into four stages: elastic stage, elastoplastic stage, plastic stage, and strain hardening stage. The predicted curve shows good agreement with the experimental results. The predicted peak loads are $3,396 \mathrm{kN}$ (SFC(E) 8) and 3,806 kN (SFC(E)9), about $2.6 \%$ and $1.1 \%$ higher than the experimental 3,310 kN (SFC(E)8) and $3,765 \mathrm{kN}$ (SFC(E)9), respectively. 


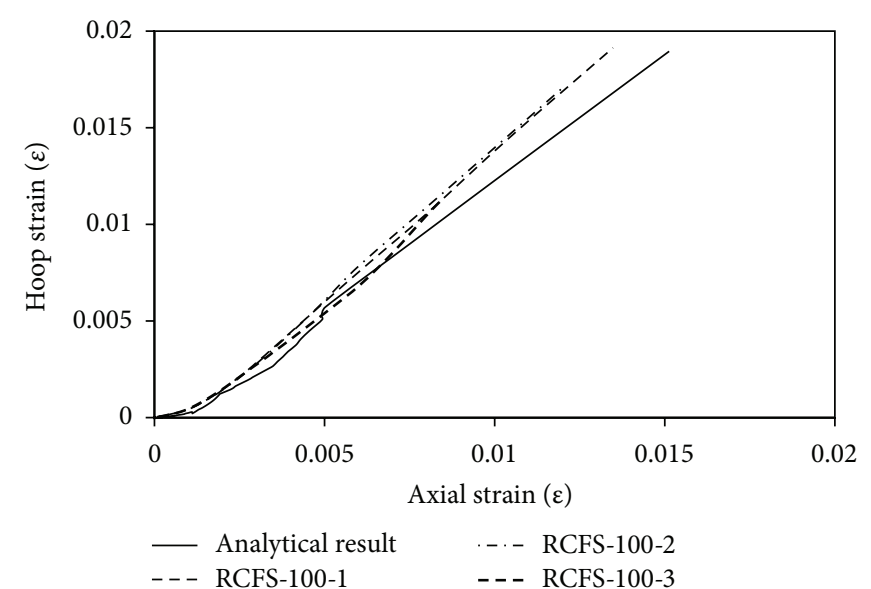

(a) RCFS-100

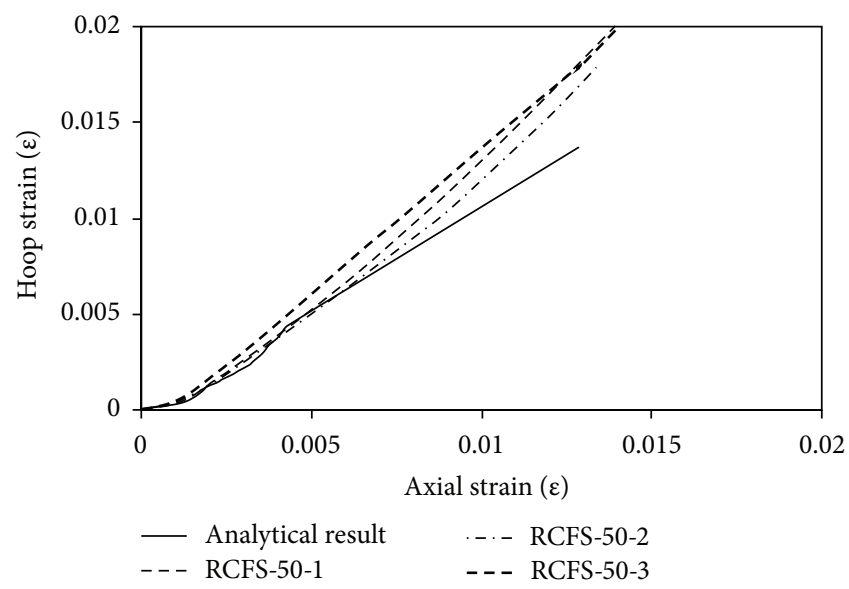

(c) RCFS-50

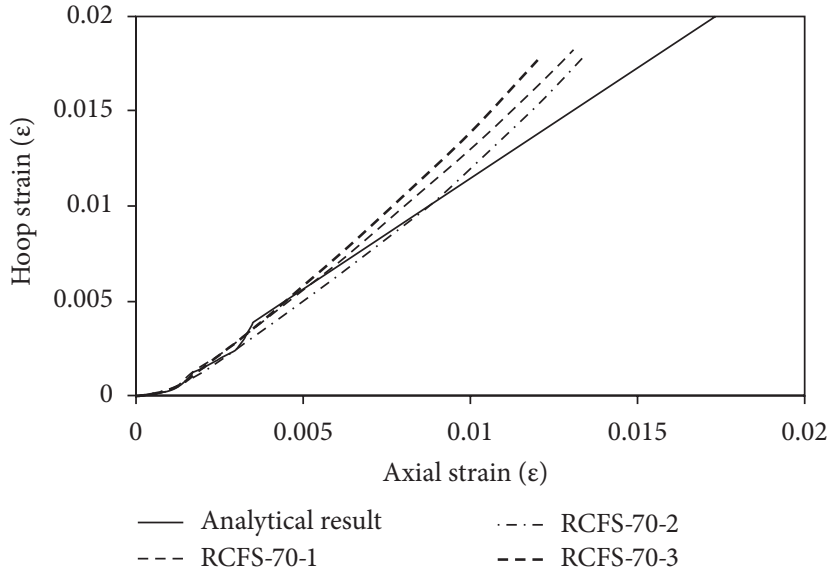

(b) RCFS-70

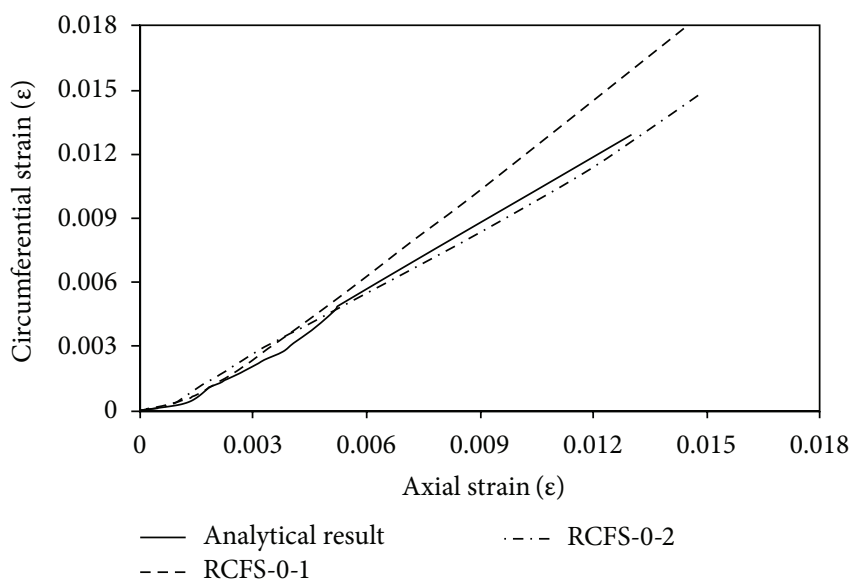

(d) RCFS-0

FIGURE 5: Strain within steel tube.

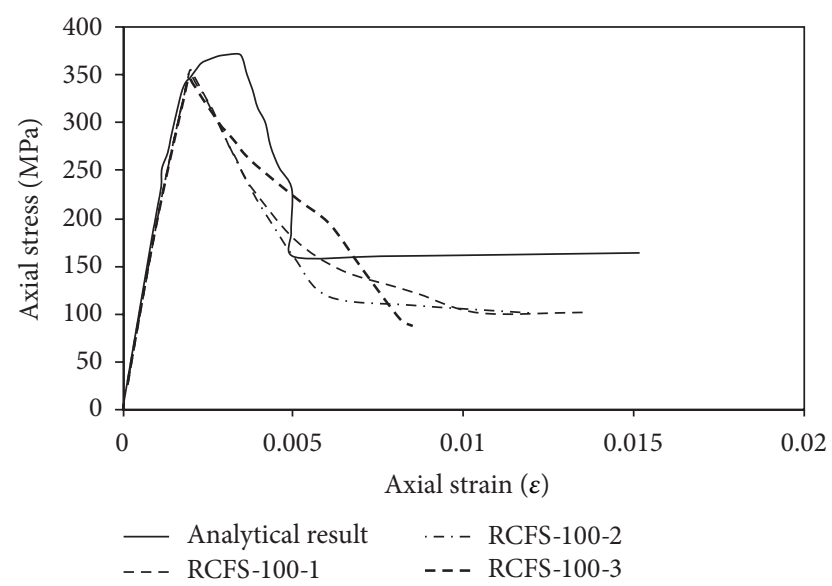

FIGURE 6: The variation of the axial compressive stress of steel tube.

In the above experiments, the prism compressive strength $\left(f_{c}\right)$, the yield strength $\left(f_{y}\right)$, and the diameter-to-thickness ratio range from 23.23 to $93.8 \mathrm{MPa}, 265.8$ to $465 \mathrm{Mpa}$, and 15.9 to 150 , respectively. The results calculated by the mechanical model match the experimental ones well. The predicted complete load-deformation responses are in good agreement with the experimental results. Therefore, this model can be used to predict the mechanical response of RACFST under axial compression.

\section{Analysis and Discussion}

Based on the above analysis results, the axial stress-strain response of the confined core concrete and the RCA effect are discussed as follows.

\subsection{Axial Stress-Strain Response}

5.1.1. The Characteristics of Axial Stress-Strain Response. The axial stress-strain relationships of the confined concrete in RACFST stub columns are shown in Figure 11. Based on the analysis results, it can be found that the curves of the confined concrete in RACFST are categorised into approximately linear ascending part, plastic part, strain hardening part, and declining part (Figure 12). This phenomenon was also found by Cetisli and Naito [31] and Huang et al. [25]. 


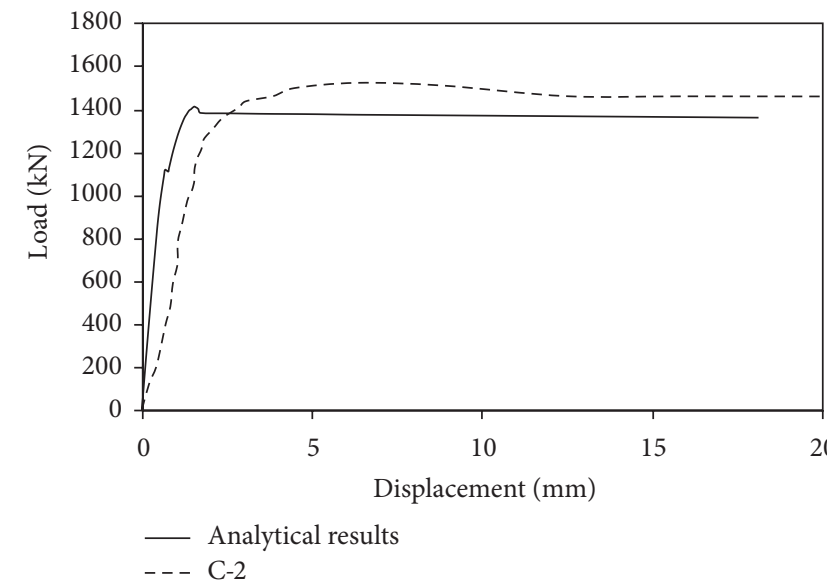

(a) $\mathrm{C}-2$

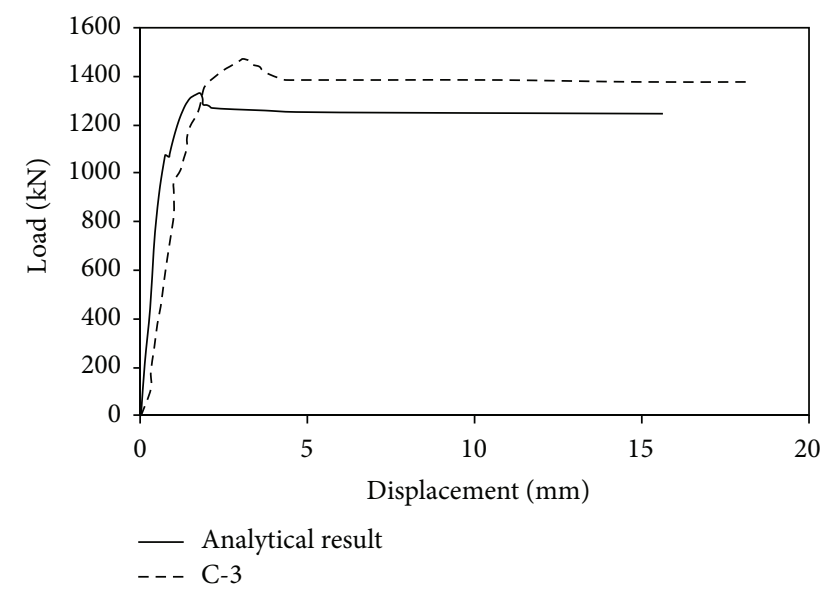

(b) C-3

FIGURE 7: The axial load-displacement relationships of specimens [15].

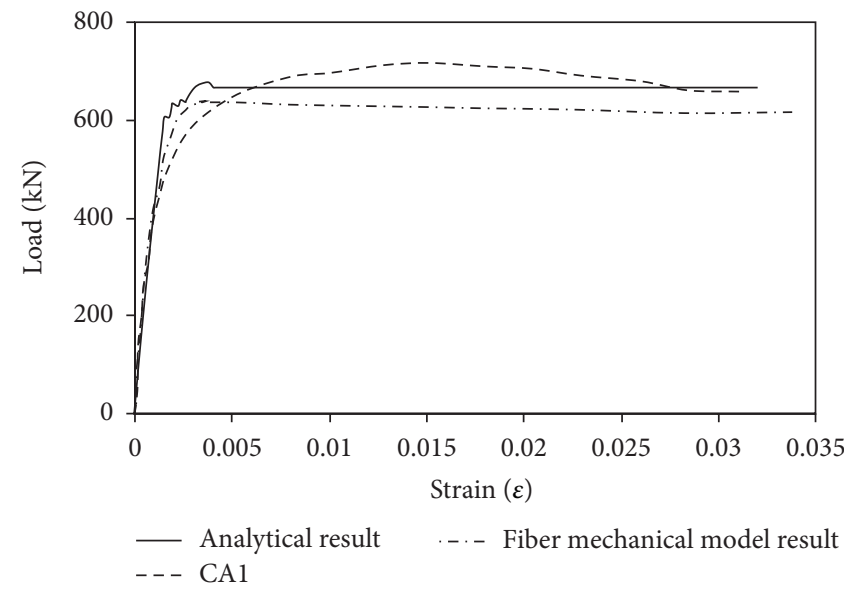

(a) CA1

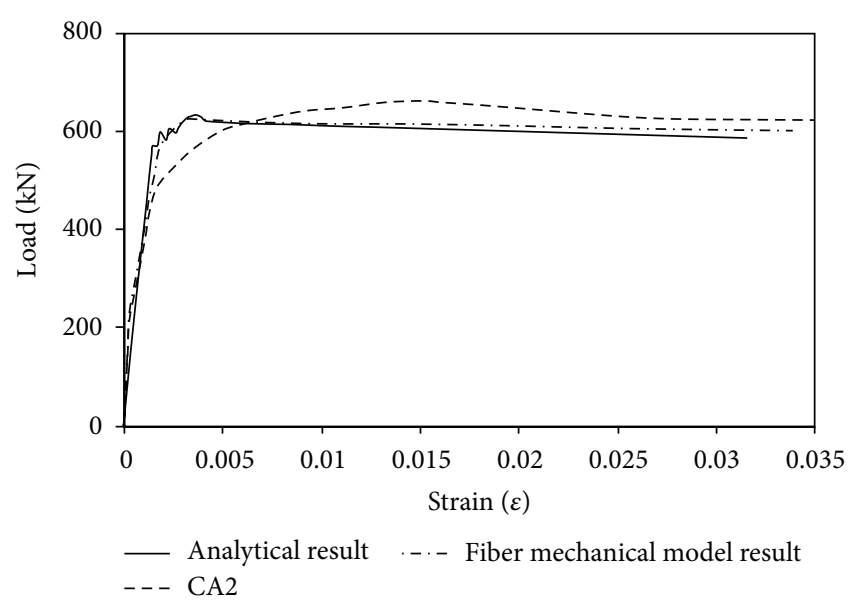

(b) $\mathrm{CA} 2$

Figure 8: The axial load-displacement relationships of specimens [14].

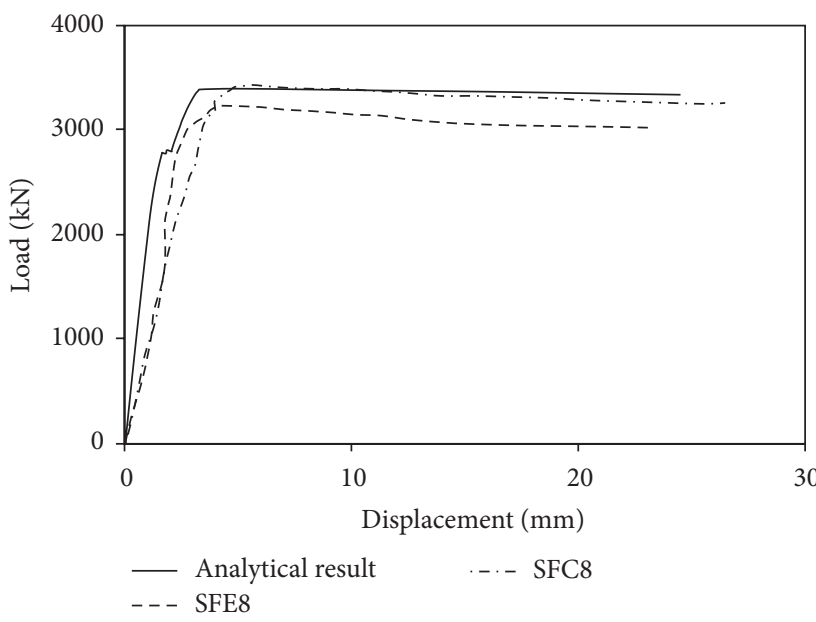

(a) $\mathrm{SFC}(\mathrm{E}) 8$

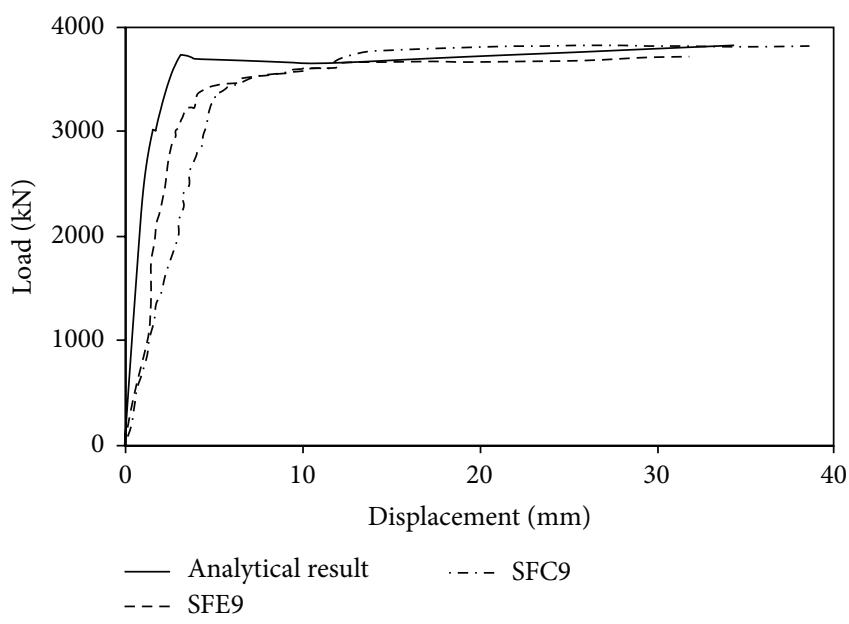

(b) $\operatorname{SFC}(\mathrm{E}) 9$

FIgURE 9: The axial load-displacement relationships of specimens [22]. 


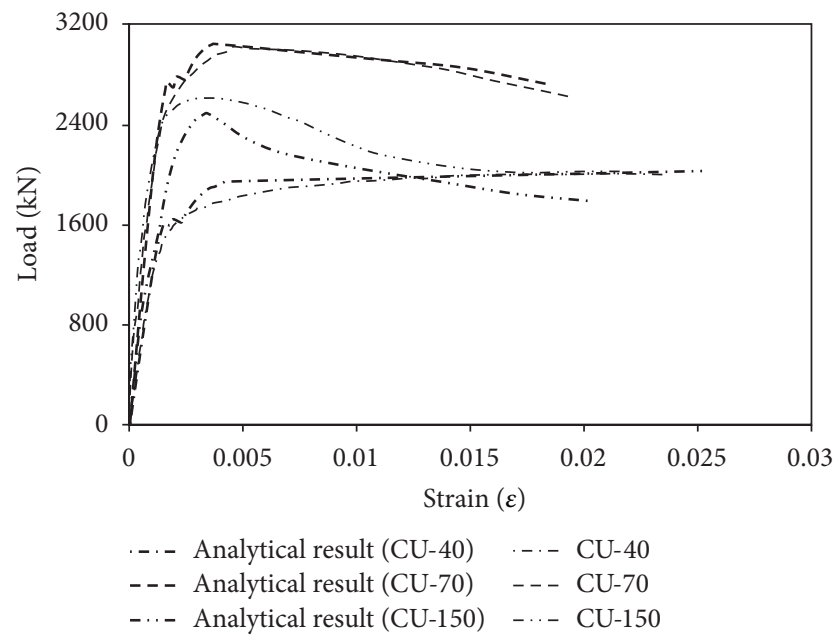

FIGURE 10: The axial load-displacement relationships of specimens [30].

The reasons for this phenomenon are the passive confinement and the composite action between the core concrete and the outer tube. In the initial stage of loading, the steel tube and the core concrete are in the elastic stage; the composite action is negligible. After that, the core concrete enters into the elastoplastic stage with the increase of load, whereas the outer steel tube constrains the lateral deformation of core concrete and restricts cracking and crushing. The axial stress is approximately proportional to the corresponding strain during this period. But, with the increase of load, the outer steel tube is in elastoplastic stage. The increase of the confining pressure becomes small and the constraint influence on the core concrete is not obvious. So the increase of confined core concrete axial stress is negligible but the increase of strain is obvious (during this period, the stress could decrease due to the lagging confinement growth). The relation between the confined core concrete axial stress and the corresponding strain is characterized by plasticity during this period. After the steel enters into plastic stage, the stress redistribution in steel tube occurs, the circumferential stress of steel tube increases rapidly, and the axial stress decreases. So, the constraining effect is improved due to the increasing confining pressure. The microcracks close, leading to increase in axial stress of the confined core concrete. The response of concrete in this stage is characterized by enhancement of stress. Finally, the axial stress reaches peak value and the curves of the core concrete begin to decline.

It is found from Figure 11 that the axial stress-strain of the confined concrete in RACFST is different from that of confined concrete under constant confinement, which can be attributed to the varying confining pressure and the composite action. The calculated curves are also different from the widely used model [21].

5.1.2. The Influencing Factors. According to the analysis results, it can be concluded that diameter-to-thickness ratio
$(D / t)$, tube thickness $(t)$, and yield strength $\left(f_{y}\right)$ have significant effects on the development of stress-strain curve, whereas the influence of constraining factor $\xi$ is mild. Take CU-40, CU-70, and CU-150 as examples; under the same concrete strength, the range of plastic stage of confined concrete in CFST decreases and the modulus of strain hardening stage increases with an increase of $t$ and decrease of $D / t$. $\xi$ of RCFS- 0 is nearly the same as that of CU-40, while the curve of the confined concrete in RCFS- 0 is different from that of concrete in CU-40. The higher yield strength is, the more plastic stage of confined concrete is.

Considering the effects of $D / t, t$, and $f_{y}$, it can be found that the confining pressure $\left(p=-2 t \sigma_{s}^{h} / D\right)$ is the crucial factor determining the response of confined concrete. However, $\xi$ has an important influence on the enhancement of core concrete strength, as shown in Figure 13. The improvement of core concrete strength increases with increase of $\xi$ value. But $D / t$ influence on the core concrete strength improvement is not obvious.

5.2. Confining Pressure. The developing tendencies of the confining pressure $(p)$ are shown in Figure 14. It can be found that the confining pressure-axial strain relationships can be categorised into negative part, approximately linear ascending part, plastic part, hardening part, and smooth part (Figure 15). $p$ provided by the outer tube does not remain constant or ideally elastoplastic. $D / t$ and $t$ have important influences on the development of $p$, while the influence of $\xi$ is not obvious. It can be found from specimen C-3 that the plastic stage of $p$ is negligible and the modulus of confining pressure-strain curve is more than that of the others.

The variation of $p$ can change the response of the confined concrete. The comparisons between the variation of $p$ and that of concrete are shown in Figure 16. In the initial loading stage, with the increases of $p$, the axial stress of concrete keeps increasing. The axial stress enters into plastic stage when the increase of $p$ is small. After that, $p$ increases quickly which leads to the enhancement of concrete strength. Finally, the confining pressure becomes constant, and the axial stress of the confined concrete decreases slightly. This phenomenon is in line with the experimental results in Cetisli and Naito [31].

\subsection{The RCA Replacement Percentage Influence}

5.3.1. The Response of Confined Core Concrete. In order to study the RCA replacement percentage effect on the response of confined concrete, the concrete strength enhancement $\left(\sigma_{c} / f_{c}\right)$ and deformation ductility $\left(\varepsilon_{c} / \varepsilon_{1}\right)$ relationships are plotted in Figure $17\left(\varepsilon_{1}\right.$ is the peak strain of plain RAC, which is calculated by Xiao et al. [6]). $f_{c}$ and $D / t$ effects are minimized, while the RCA replacement percentage influence is considered. It can be found that, under similar steel tube confinement (i.e., $D, t, f_{y}$, and $f_{c}$ ), the RCA replacement percentage has slight effect on the responses of concrete. The peak strength enhancements of the core concrete in RCFS-50 and RCFS-100 are 2.05 and 2.38, respectively; and 


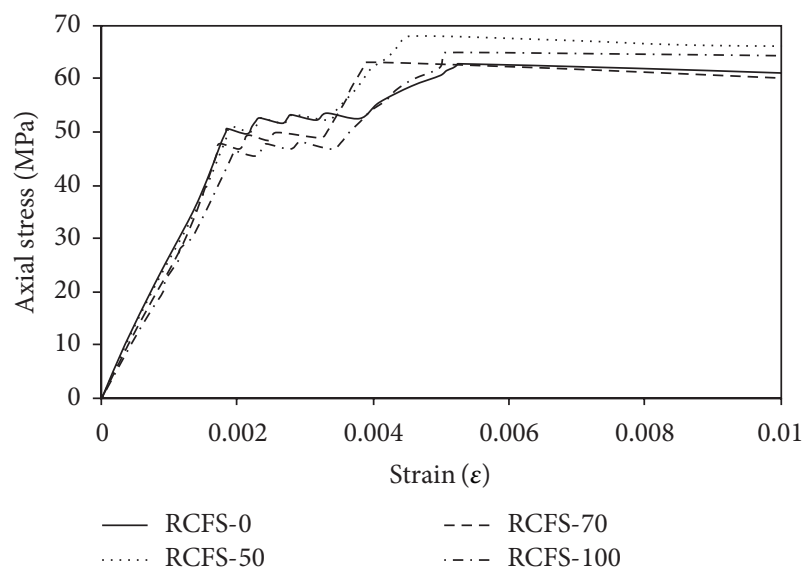

(a) RCFS

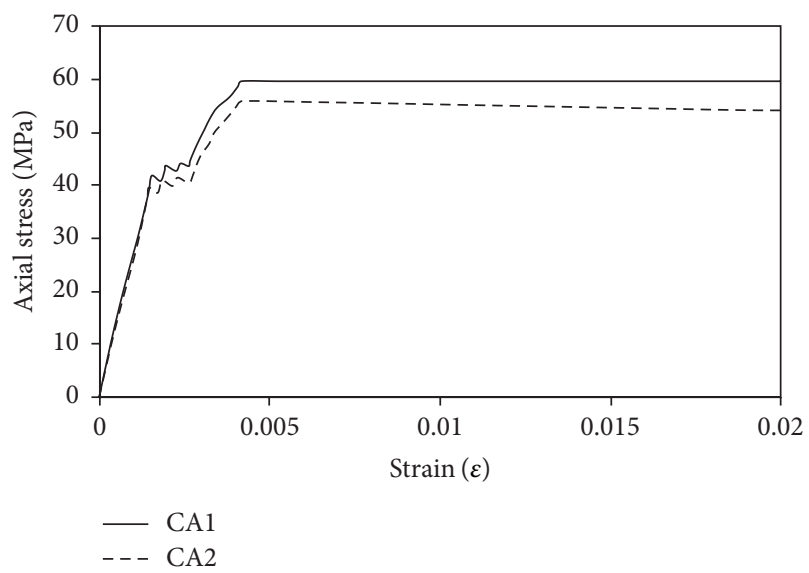

(c) CA series

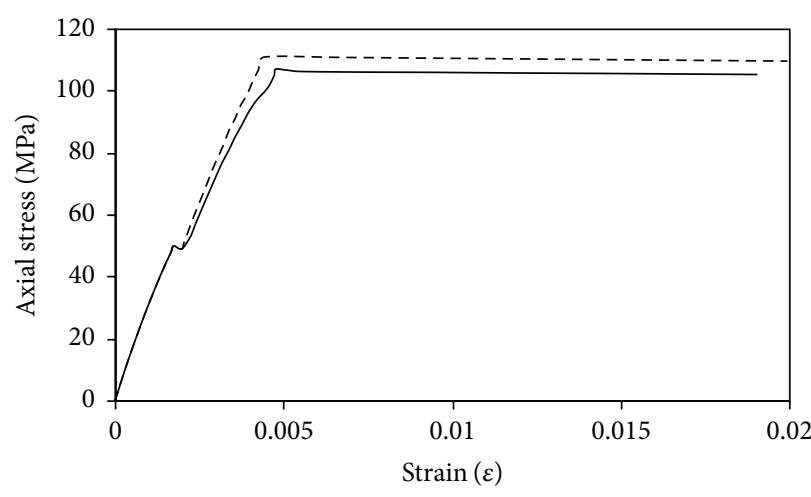

- C-2

-.- C-3

(b) C series

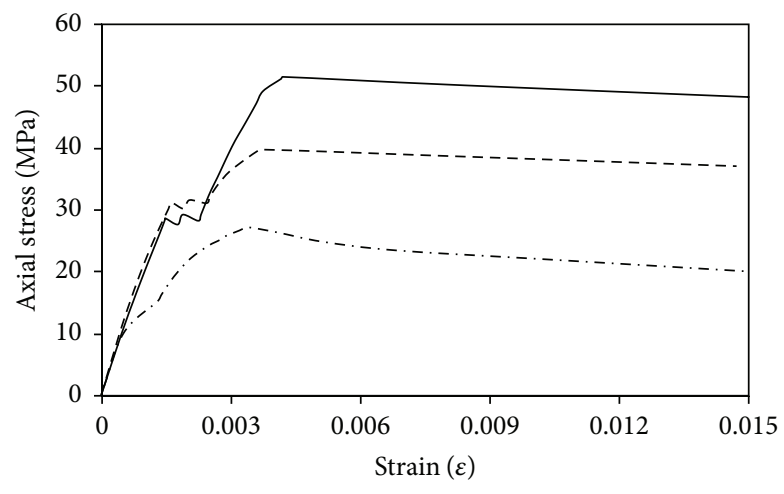

... CU-150

(d) CU series

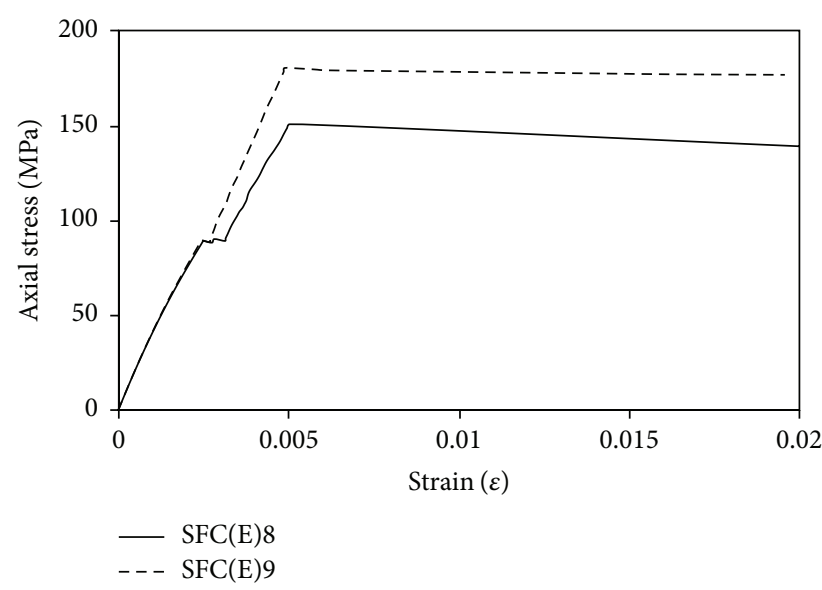

(e) $\operatorname{SFC}(E)$ series

FIgURE 11: The calculated axial stress-strain relationships of confined core concrete.

the corresponding peak deformation ductility are 2.07 and 2.39 , respectively. The peak deformation ability and the peak strength enhancement increase with an increase of RCA replacement percentage (Table 2 ).

It should be also noted that the differences in the approximately linear ascending stage of concrete are negligible because the cracking/crushing does not widely develop and the RCA contents influence is not obvious. The differences become obvious with the increase of load due to RCA accelerating the deterioration of core concrete.

5.3.2. The Confining Pressure. The RCA replacement percentage influence on the confining pressure $(p)$ is shown in Figure 18. It can be found that, under the same $D, t$, and $f_{y}$ 


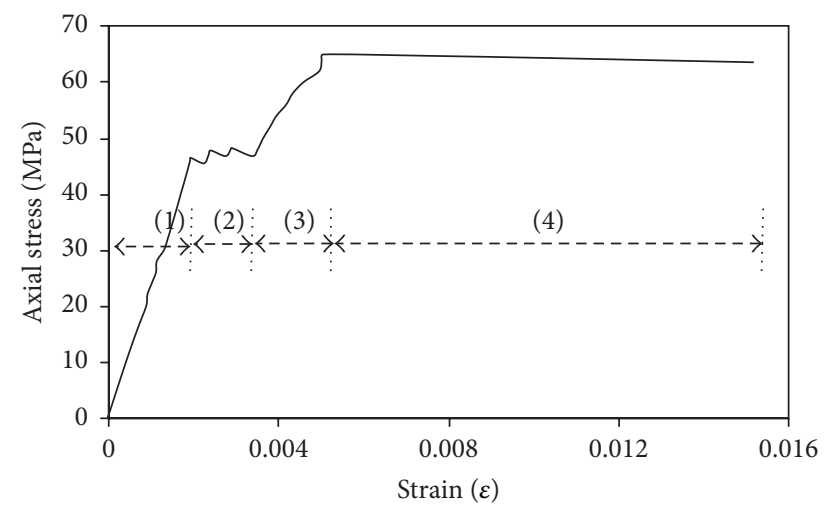

(1) Linear ascending

(2) Plastic

(3) Strain hardening

(4) Descending

FIGURE 12: The stages of confined core concrete.

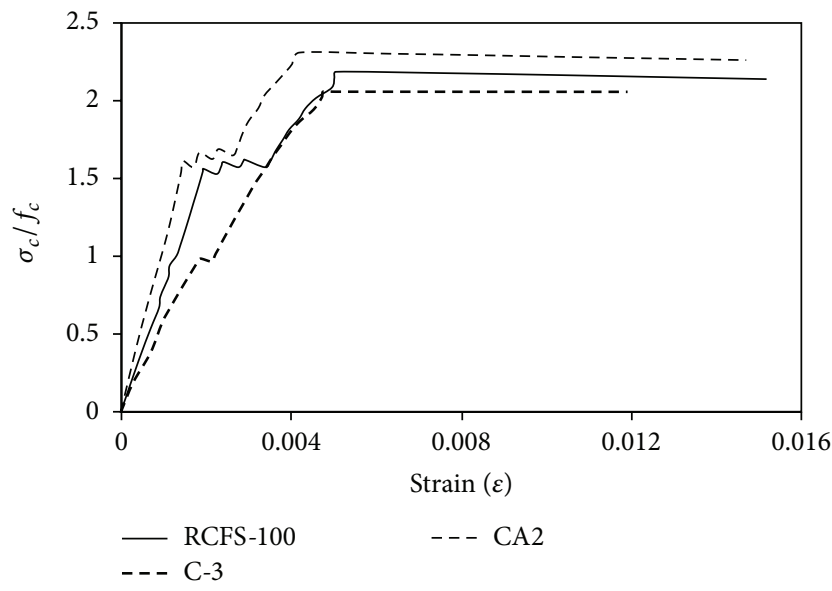

Figure 13: The enhancement of core concrete strength.

and so forth, the ratio of $p$ to $\sigma_{c}$ changes irregularly and the RCA effect is not obvious. However, in the declining stage, the more RCA replacement percentage is, the better concrete strength enhancement and deformation ability are.

\section{Conclusions}

The mechanical behaviour of RACFST stub columns under axial compression is analysed and discussed in this paper. The following conclusions can be drawn:

(1) A new mechanical model of RACFST is developed and the corresponding numerical program is established. The analytical results are compared with various experimental results. The results calculated by the mechanical model match the real ones well. The predicted complete load-deformation response and peak load are in good agreement with the experimental results.

(2) The axial stress-strain relationship of the confined concrete in RACFST stub column can be categorised into approximately linear ascending part, plastic part,

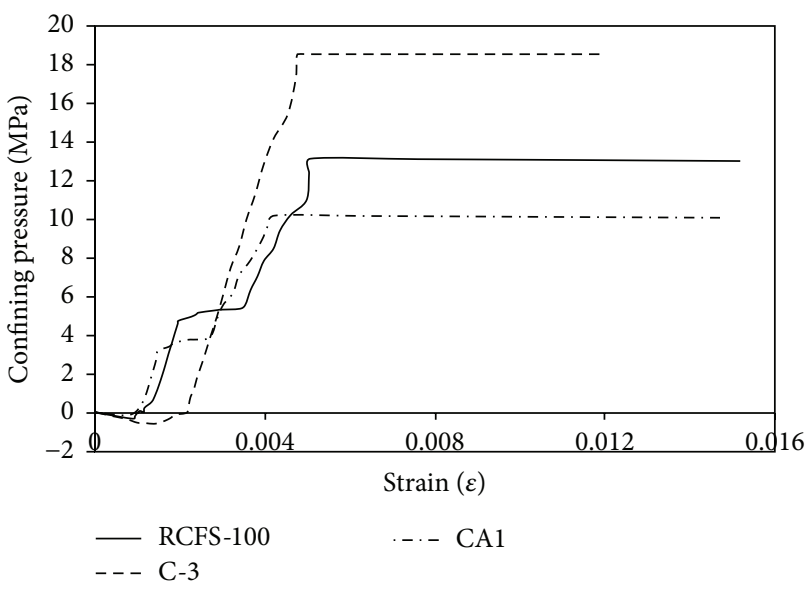

FIGURE 14: The variation of the confining pressure.

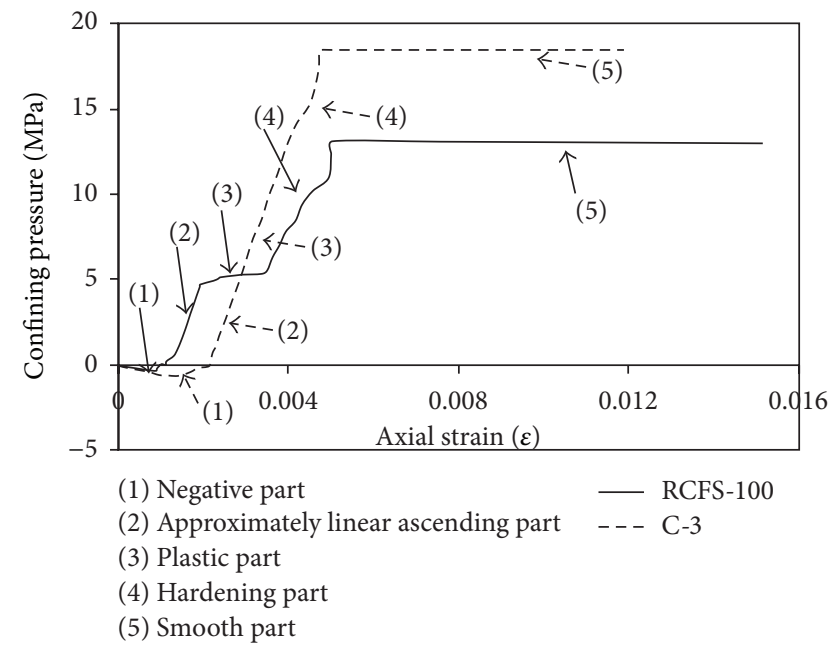

FIGURE 15: The stages of the confining pressure.

strain hardening part, and declining part. The axial stress-strain of the core concrete in RACFST is different from that of the confined core concrete under constant confinement.

(3) The confining pressure varies during the whole period. The development of confining pressure in CFST is divided into negative part, approximately linear ascending part, plastic part, hardening part, and smooth part. This tendency is different from the development of confining pressure in fiber reinforced polymer (FRP) confined concrete (there is no obvious plastic and smooth part). The variation of the confining pressure could lead to the change of confined concrete response.

(4) Compared with the constraining factor, the confining pressure has obvious effect on the developing tendency of core concrete stress-strain relationship and confining pressure. $\xi$ has an important influence on the enhancement of core concrete strength. 


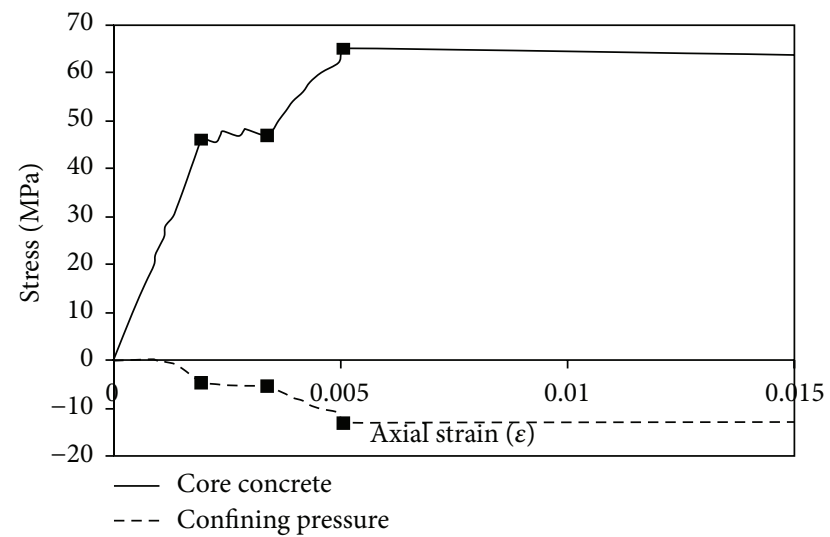

FIGURE 16: The comparisons between the axial stress-strain relationship of core concrete and the variation of confining pressure.

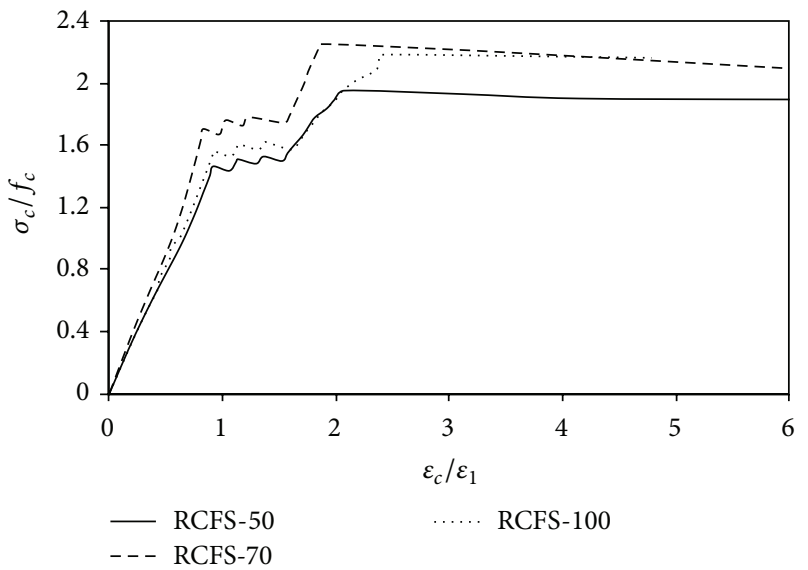

FIGURE 17: The concrete strength enhancement-strain ductility relationship.

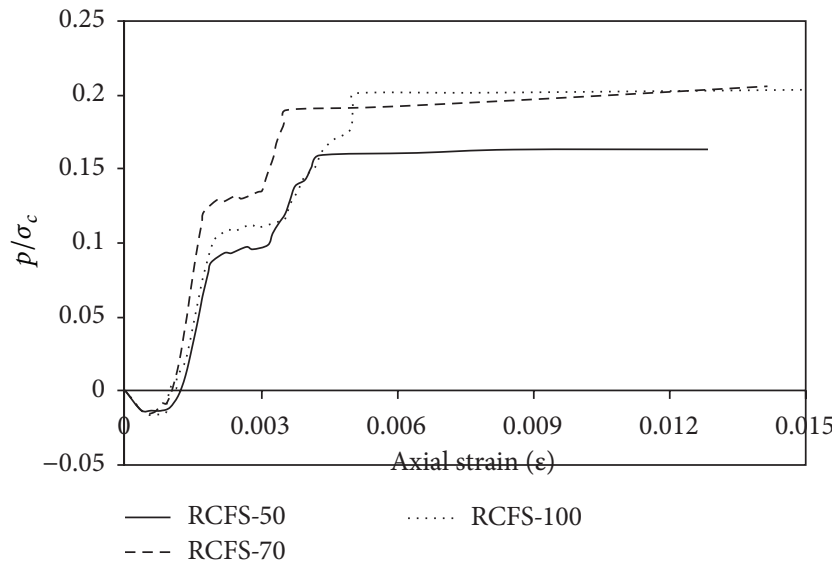

FIgURE 18: The $p / \sigma_{c}$-strain relationship.

(5) Under the same steel tube confinement, the RCA replacement percentage has slight influence on the mechanical behaviours of confined core concrete. The peak deformation ability and the peak strength enhancement increase with an increase of RCA replacement percentage. In the declining stage,
TABLE 2: The influence of recycled coarse aggregate.

\begin{tabular}{lccccc}
\hline & Specimen & $\xi$ & $r$ & $\begin{array}{c}\text { Peak strength } \\
\text { enhancement }\end{array}$ & $\begin{array}{c}\text { Peak } \\
\text { deformation } \\
\text { ductility }\end{array}$ \\
\hline \multirow{3}{*}{ Xiao et al. } & RCFS-100 & 1.21 & $100 \%$ & 2.38 & 2.39 \\
{$[18]$} & RCFS-70 & 1.28 & $70 \%$ & 2.41 & 1.98 \\
\hline
\end{tabular}

the more RCA replacement percentage is, the better concrete strength enhancement and deformation ability are.

\section{Notations}

\begin{tabular}{|c|c|}
\hline$D, t:$ & $\begin{array}{l}\text { Diameter and thickness of steel tube, } \\
\text { respectively }\end{array}$ \\
\hline$f_{c}:$ & $\begin{array}{l}\text { Prism compressive strength of core } \\
\text { concrete }\end{array}$ \\
\hline$E_{s}, E_{s}^{\prime}:$ & $\begin{array}{l}\text { Elastic modulus and elastic-plastic } \\
\text { modulus of steel tube, respectively }\end{array}$ \\
\hline$E_{o}, E_{c}^{t}:$ & $\begin{array}{l}\text { Elastic modulus and tangent modulus } \\
\text { of core concrete, respectively }\end{array}$ \\
\hline$I_{1}, J_{2}$, and $\sigma_{1}$ : & $\begin{array}{l}\text { First stress invariant, second stress } \\
\text { invariant, and first principal stress }\end{array}$ \\
\hline$N, N_{s}$, and $N_{c}$ : & $\begin{array}{l}\text { Axial loads of specimen, steel tube, } \\
\text { and core concrete, respectively }\end{array}$ \\
\hline$p:$ & Confining pressure \\
\hline$r:$ & $\begin{array}{l}\text { Recycled coarse aggregate } \\
\text { replacement percentage }\end{array}$ \\
\hline$\beta:$ & Nonlinear index \\
\hline$d \varepsilon_{c}^{r}, d \varepsilon_{c}^{a}$, and $d \varepsilon_{c}^{h}$ : & $\begin{array}{l}\text { Radial, axial, and circumferential } \\
\text { strain increments of core concrete, } \\
\text { respectively }\end{array}$ \\
\hline $\bar{\varepsilon}:$ & Equivalent strain \\
\hline$d \sigma_{c}^{r}, d \sigma_{c}^{a}$, and $d \sigma_{c}^{h}$ : & $\begin{array}{l}\text { Radial, axial, and circumferential } \\
\text { stress increments of core concrete, } \\
\text { respectively }\end{array}$ \\
\hline $\bar{\sigma}:$ & Equivalent stress \\
\hline$\mu_{s}, \mu_{s}^{\prime}:$ & $\begin{array}{l}\text { Poisson's ratio of steel in elastic and } \\
\text { elastic-plastic stage, respectively }\end{array}$ \\
\hline$\xi:$ & Constraining factor. \\
\hline
\end{tabular}

\section{Conflict of Interests}

The authors declare that there is no conflict of interests regarding the publication of this paper.

\section{Acknowledgments}

The authors wish to acknowledge the financial support from the National Natural Science Foundation of China (NSFC) (no. 51408346), the Shandong University of Science and Technology (no. 01156010905), and the Taishan Scholarship Project of Shandong Province (no. tshw20130956). The authors also wish to acknowledge the collaboration of 
Professors Jianzhuang Xiao and Zhenjun Yang in the English revision work.

\section{References}

[1] T. C. Hansen, "Recycled aggregates and recycled aggregate concrete second state-of-the-art report developments 19451985," Materials and Structures, vol. 19, no. 3, pp. 201-246, 1986.

[2] A. P. Kevin, J. C. David, and K. D. Ravindra, "Strength and deformation characteristics of concrete containing coarse recycled and manufactured aggregates," in Proceedings of the 11th International Conference on Non-conventional Materials and Technologies, pp. 2084-2088, Bath, UK, 2009.

[3] T. C. Hansen and E. Boegh, "Elasticity and drying shrinkage of recycled aggregate concrete," ACI Journal, vol. 82, pp. 648-652, 1986.

[4] A. Ajdukiewicz and A. Kliszczewicz, "Influence of recycled aggregates on mechanical properties of HS/HPC," Cement and Concrete Composites, vol. 24, no. 2, pp. 269-279, 2002.

[5] N. Otsuki, S. Miyazato, and W. Yodsudjai, "Influence of recycled aggregate on interfacial transition zone, strength, chloride penetration and carbonation of concrete," Journal of Materials in Civil Engineering, vol. 15, no. 5, pp. 443-451, 2003.

[6] J. Z. Xiao, J. B. Li, and C. Zhang, "Mechanical properties of recycled aggregate concrete under uniaxial loading," Cement and Concrete Research, vol. 35, no. 6, pp. 1187-1194, 2005.

[7] Y. F. Yang, L. H. Han, and X. Wu, "Concrete shrinkage and creep in recycled aggregate concrete-filled steel tubes," Advances in Structural Engineering, vol. 11, no. 4, pp. 383-396, 2008.

[8] P. J. Terrey, M. A. Bradford, and R. I. Gilbert, "Creep and shrinkage in concrete filled steel tubes," in Proceedings of the 6th International Symposium on Tubular Structures, pp. 293-298, Melbourne, Australia, December 1994.

[9] H. Nakai, A. Kurita, and L. H. Ichinose, "An experimental study on creep of concrete filled steel pipes," in Proceedings of the 3rd International Conference on Steel-Concrete Composite Structures, pp. 55-60, Fukuoka, Japan, September 1991.

[10] L. H. Ichinose, E. Watanabe, and H. Nakai, "An experimental study on creep of concrete filled steel pipes," Journal of Constructional Steel Research, vol. 57, no. 4, pp. 453-466, 2001.

[11] L.-H. Han, Y.-F. Yang, and Z. Tao, "Concrete-filled thin-walled steel SHS and RHS beam-columns subjected to cyclic loading," Thin-Walled Structures, vol. 41, no. 9, pp. 801-833, 2003.

[12] A. Fam, F. S. Qie, and S. Rizkalla, "Concrete-filled steel tubes subjected to axial compression and lateral cyclic loads," Journal of Structural Engineering, vol. 130, no. 4, pp. 631-640, 2004.

[13] K. Konno and Y. Sato, "Propriety of recycled aggregate concrete column encased by steel tube subjected to axial compression," Transactions of the Japan Concrete Institute, vol. 19, no. 2, pp. 231-238, 1997.

[14] Y. F. Yang, "Performance of recycled aggregate concrete-filled steel tubular members under various loadings," in Proceedings of the 2nd International Conference on Waste Engineering and Management (ICWEM '10), pp. 475-484, Shanghai, China, October 2010.

[15] J. Chen and L. Zeng, "Experiment on mechanical performance of axial compression of recycled concrete-filled steel tubular stub columns," Journal of Lanzhou University of Technology, vol. 39, pp. 112-116, 2013 (Chinese).

[16] Z. P. Chen, X. H. Chen, X. J. Ke, and J. Y. Xue, "Experimental study on the mechanical behavior of recycled aggregate coarse concrete-filled square steel tube column," in Proceedings of the International Conference on Mechanic Automation and Control Engineering (MACE '10), pp. 1198-1201, Wuhan, China, 2010.

[17] Z.-P. Chen, F. Liu, H.-H. Zheng, and J.-Y. Xue, "Research on the bearing capacity of recycled aggregate concrete-filled circle steel tube column under axial compression loading," in Proceedings of the International Conference on Mechanic Automation and Control Engineering (MACE '10), pp. 1198-1201, Wuhan, China, June 2010.

[18] J. Z. Xiao, Y. J. Huang, J. Yang, and Ch. Zhang, "Mechanical properties of confined recycled aggregate concrete under axial compression," Construction and Building Materials, vol. 26, no. 1, pp. 591-603, 2012.

[19] Y. X. Liu, X. X. Zha, and G. B. Gong, "Study on RecycledConcrete-Filled Steel Tube and recycled concrete based on damage mechanics," Journal of Constructional Steel Research, vol. 71, pp. 143-148, 2012.

[20] B. Wu, X. Y. Zhao, Q. X. Liu, and J. S. Zhang, "Full-scale axial loading tests of concrete-filled cteel tubular columns incorporating demolished concrete slumps," in Proceedings of the 2nd International Conference on Waste Engineering and Management, pp. 475-484, Shanghai, China, 2010.

[21] L.-H. Han, G.-H. Yao, and X.-L. Zhao, "Tests and calculations for hollow structural steel (HSS) stub columns filled with selfconsolidating concrete (SCC)," Journal of Constructional Steel Research, vol. 61, no. 9, pp. 1241-1269, 2005.

[22] M. Johansson, "The efficiency of passive confinement in CFT columns," Steel and Composite Structures, vol. 2, no. 5, pp. 379396, 2002.

[23] L.-H. Han, G.-H. Yao, and Z. Tao, "Performance of concretefilled thin-walled steel tubes under pure torsion," Thin-Walled Structures, vol. 45, no. 1, pp. 24-36, 2007.

[24] L. H. Han and S. T. Zhong, The Mechanics of Concrete Filled Steel Tubes, Dalian University of Technology Press, Dalian, China, 1996, (Chinese).

[25] Y. Huang, J. Xiao, and C. Zhang, "Theoretical study on mechanical behavior of steel confined recycled aggregate concrete," Journal of Constructional Steel Research, vol. 76, pp. 100-111, 2012.

[26] Z. H. Guo and X. D. Shi, Reinforced Concrete Theory and Analyses, Tsinghua University Press, Beijing, China, 2003.

[27] Y. J. Huang, On the mechanical behaviour of steel and GFRP tube confined recycled concrete columns [Ph.D. thesis], Tongji University, Shanghai, China, 2013, (Chinese).

[28] S. S. Hsieh, E. C. Ting, and W. F. Chen, "A plastic-fracture model for concrete," International Journal of Solids and Structures, vol. 18, no. 3, pp. 181-197, 1982.

[29] N. S. Ottosen, "Constitutive model for short-time loading of concrete," Journal of the Engineering Mechanics Division, vol. 105, no. 1, pp. 127-141, 1979.

[30] C. S. Huang, Y.-K. Yeh, G.-Y. Liu et al., "Axial load behavior of stiffened concrete-filled steel columns," Journal of Structural Engineering, vol. 128, no. 9, pp. 1222-1230, 2002.

[31] F. Cetisli and C. J. Naito, "Concrete subjected to varying confinement, I: experimental evaluation," Journal of Advanced Concrete Technology, vol. 7, no. 2, pp. 239-249, 2009. 


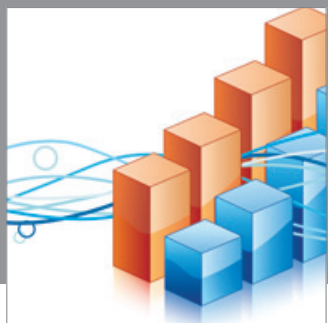

Advances in

Operations Research

mansans

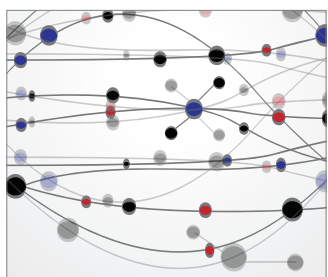

The Scientific World Journal
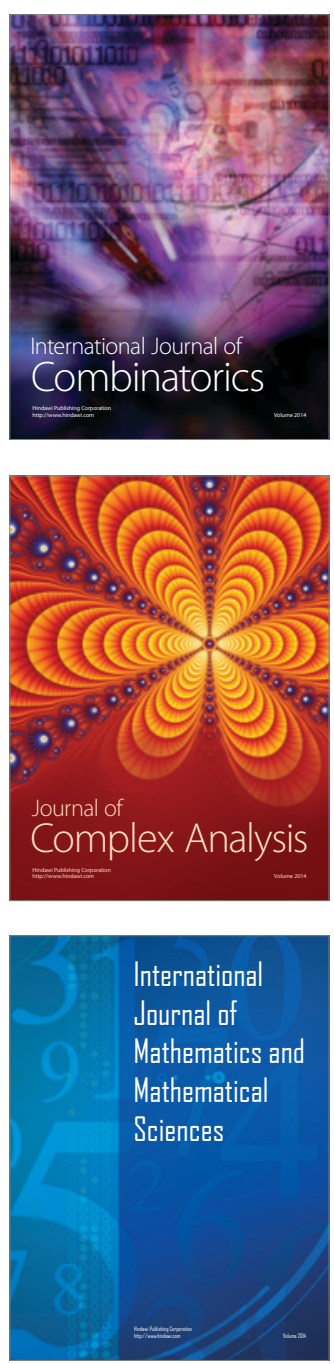
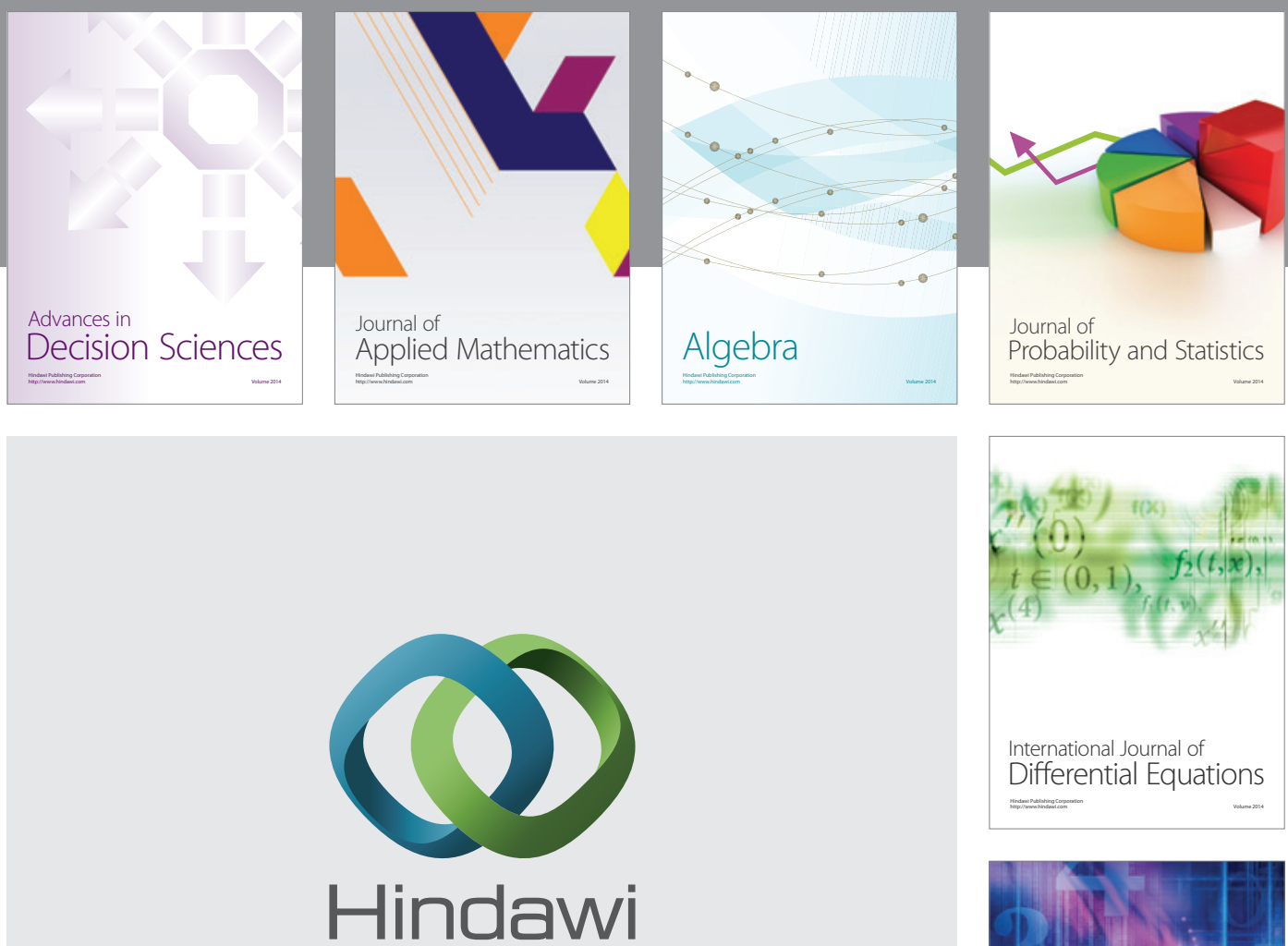

Submit your manuscripts at http://www.hindawi.com
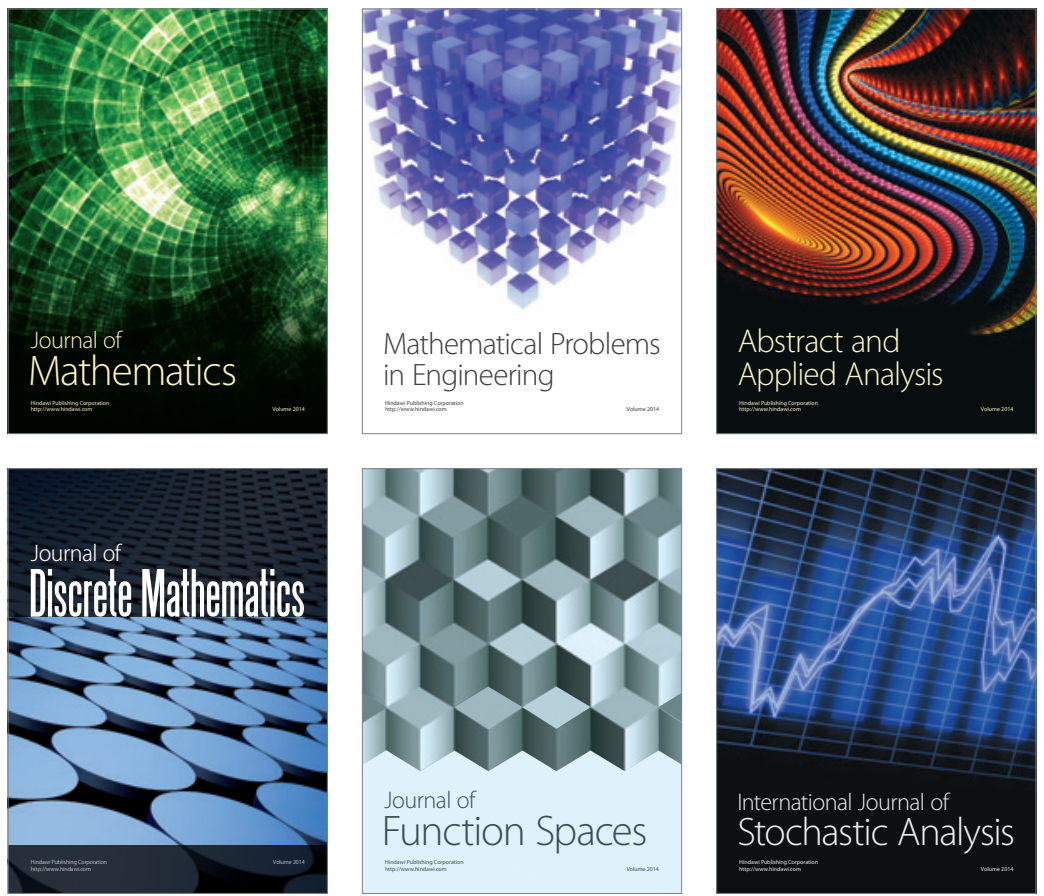

Journal of

Function Spaces

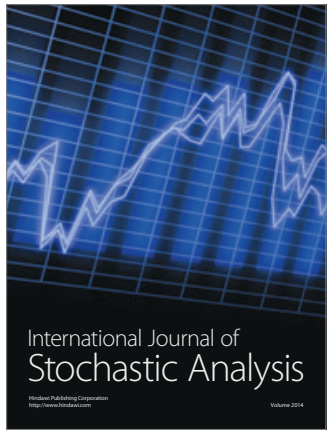

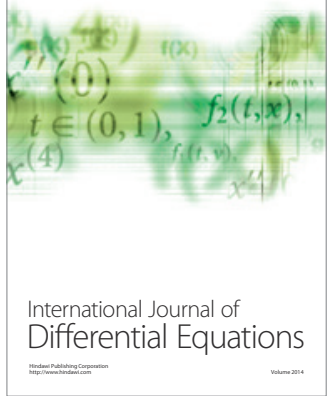
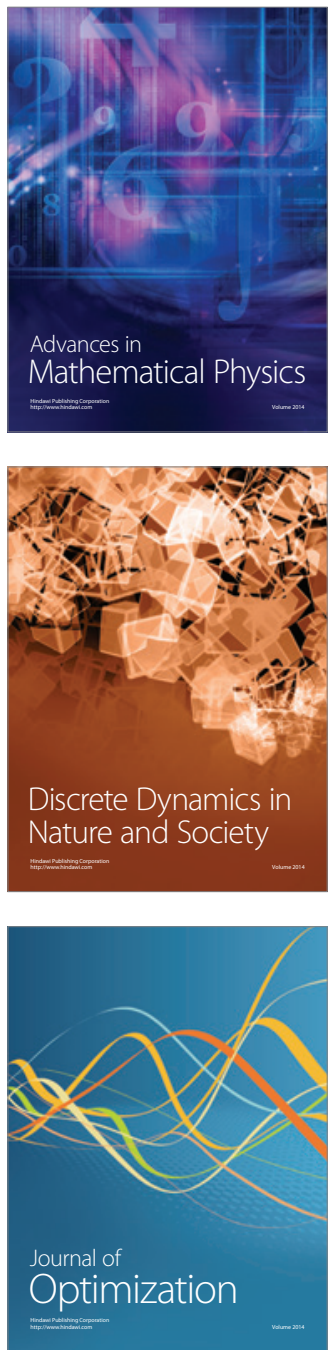